\title{
LA TRANSFORMACIÓN DE FRONTEX EN LA AGENCIA EUROPEA DE LA GUARDIA DE FRONTERAS Y COSTAS: ¿̇HACIA UNA CENTRALIZACIÓN EN LA GESTIÓN DE LAS FRONTERAS?
}

\author{
JUAN SANTOS VARA ${ }^{1}$ \\ Universidad de Salamanca \\ savajuan@usal.es
}

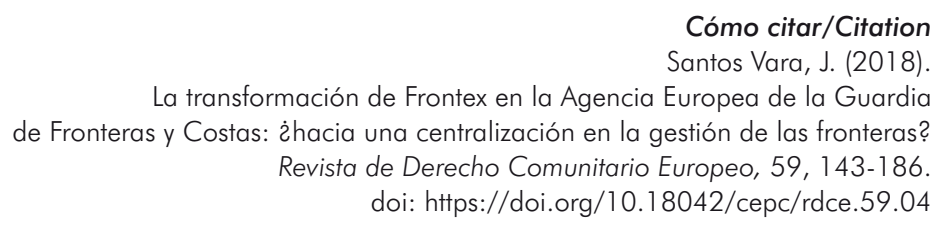

Resumen

A pesar de que el Reglamento de la Guardia Europea de Fronteras y Costas (GEFC) ha reforzado significativamente las funciones conferidas a la Agencia Frontex, esta transformación no supone realmente que se haya producido una transformación en la naturaleza jurídica de la Agencia. Los cambios introducidos

1 Profesor titular de Derecho Internacional Público y Relaciones Internacionales, titular de la cátedra Jean Monnet en Acción Exterior (Universidad de Salamanca). Este trabajo se ha realizado en el marco del proyecto de investigación «Control democrático y acción exterior» (EUDECEXT), DER2015-70082-P, del que el autor es investigador principal. Agradezco a los evaluadores anónimos los comentarios realizados sobre el presente trabajo. 
en la configuración de la Agencia no se podrían calificar de revolución, sino más bien de evolución natural en el proceso que se inició en 2004 con la creación de Frontex. Además, en el Reglamento de la GEFC se reitera constantemente que la responsabilidad principal en la gestión de las fronteras exteriores corresponde a los Estados miembros. El establecimiento de la GEFC y la expansión de los poderes de la Agencia han generado muchas expectativas. El riesgo es que estas expectativas no se vean plenamente satisfechas en el futuro y que se genere más frustración en la sociedad civil y aumente la falta de credibilidad de la UE si no es capaz de proporcionar soluciones satisfactorias ante los desafíos que se planteen en la gestión de las fronteras en los próximos años.

\title{
Palabras clave
}

Frontex; Guardia Europea de Fronteras y Costas; gestión de fronteras; agencias de la UE; operaciones de búsqueda y salvamento en el mar; relaciones exteriores de las agencias.

\section{THE TRANSFORMATION OF FRONTEX INTO THE EUROPEAN BORDER AND COAST GUARD AGENCY: TOWARDS A CENTRALIZATION IN BORDER MANAGEMENT?}

\begin{abstract}
Even though the Regulation on the European Border and Coast Guard (EBCG) has significantly reinforced the tasks conferred upon the Agency Frontex, these innovations do not entail a real transformation of its legal nature. The changes introduced in the configuration of the Agency cannot be qualified as revolutionary but more as a natural evolution in the process initiated in 2004 with the creation of Frontex. Also, the Regulation on the EBCG constantly repeats that the main responsability for the management of the external borders falls to the Member States. The establishment of the EBCG and the expansion of the powers of the Agency have generated many expectations. The risk is that the EBCG would not live up to these expectations in the future and the failures of the EBCG could lead to more frustration in civil society, ultimately increasing the lack of credibility in the EU if it is incapable of delivering satisfactory solutions to the challenges in border management that it will face in the coming years.
\end{abstract}

\section{Keywords}

Frontex; European Border and Coast Guard; border management; EU agencies; search and rescue at sea; external relations of the EU agencies. 


\section{LA TRANSFORMATION DE FRONTEX EN AGENCE EUROPÉENNE DE GARDE- FRONTIÈRES ET DE GARDE-CÔTES: VERS UNE CENTRALISATION DANS LA GESTION DES FRONTIÈRES?}

\section{Résumé}

Bien que le Règlement relatif au corps européen de garde-frontières et de gardecôtes ait renforcé significativement les fonctions attribuées à l'agence Frontex, cette transformation ne suppose pas qu'elle ait eu lieu aussi véritablement dans la nature juridique de l'agence. Les changements introduits dans la configuration de l'agence ne pourraient pas être qualifiés de révolution mais d'évolution naturelle du processus initié en 2004 avec la création de Frontex. En outre, le Règlement relatif au corps européen de garde-frontières et de garde-côtes répète - de manière constante- que les États-membres sont les principaux responsables de la gestion des frontières extérieures. La création du corps de garde-frontières et de garde-côtes et l'expansion des pouvoirs de l'agence ont donné lieu à de nombreuses expectatives. Si celles-ci ne sont pas capables d'apporter des solutions satisfaisantes face aux défis posés par la gestion des frontières dans les années prochaines, on court le risque d'accroître la frustration dans la société civile et d'augmenter le manque de crédibilité de l'UE.

\section{Mots clés}

Frontex; corps européen de garde-frontières et de garde-côtes; gestion des frontières; agences de l'UE; opérations de recherche et de sauvetage en mer; relations extérieures des agences. 


\section{SUMARIO}

I. INTRODUCCIÓN. II. EL CONCEPTO DE GESTIÓN INTEGRADA DE LAS FRONTERAS. III. LA IMPLEMENTACIÓN DE LOS NUEVOS PODERES DE LA AGENCIA EUROPEA DE LA GEFC: 1. La evaluación de vulnerabilidad. 2. El establecimiento de los contingentes de reacción rápida. 3. El denominado «derecho a intervenir». 4. El desarrollo de los hotspots. 5. El refuerzo del papel de la Agencia en materia de retorno. 6. El refuerzo del mandato de la Agencia para el tratamiento de datos de carácter personal. IV. LA GUARDIA EUROPEA DE COSTAS: UN CONCEPTO GRANDILOCUENTE. V. LA ATRIBUCIÓN A FRONTEX DE ACTIVIDADES SAR. VI. LAS RELACIONES EXTERIORES DE LA AGENCIA. VII. EL NUEVO MECANISMO DE DENUNCIA: UNA SOLUCIÓN INSATISFACTORIA PARA PROTEGER LOS DERECHOS FUNDAMENTALES. VIII. CONCLUSIONES. BIBLIOGRAFIA.

\section{INTRODUCCIÓN}

El flujo migratorio sin precedentes que ha tenido lugar en Europa en los últimos años ha generado una intensa actividad política y legislativa a partir de la adopción de la Agenda Europea de Inmigración de 2015² (González Vega, 2017; Spijkerboer, 2016; Den Heijer et al., 2016; Thym, 2016). El establecimiento de la Guardia Europea de Fronteras y Costas (GEFC) constituye una de las principales iniciativas emprendidas por la UE para hacer frente a la crisis de los refugiados ${ }^{3}$. La GEFC está compuesta por la Agencia Europea de

2 Comunicación de la Comisión al Parlamento Europeo, el Consejo Europeo y Consejo. Una Agenda Europea de Migración, COM (2015) 240 final, 13.5.2015.

3 La propuesta de la Comisión fue presentada en diciembre de 2015 y al término del verano de 2016 fue adoptada. Propuesta del Parlamento y del Consejo sobre Guardia Europea de Fronteras y Costas y por el que se derogan el Reglamento (CE) 2007/2004, el Reglamento (CE) 863/2007 y la Decisión 2005/267/CE, COM (2015) 671 final (15 de diciembre de 2015). Reglamento (UE) 2016/1624 del PE y del Consejo, de 14 de septiembre de 2016, sobre la Guardia Europea de Fronteras y Costas, por el que se modifica el Reglamento (UE) 2016/399 del PE y del Consejo y por el que se derogan el Reglamento (CE) 863/2007 del PE y del Consejo, el Reglamento (CE) 2007/2004 del Consejo y la Decisión 2005/267/CE del Consejo (DOUE L 251, de 16 de septiembre de 2016, p. 1). 
la Guardia de Fronteras y Costas y las autoridades nacionales de los Estados miembros responsables de la gestión de las fronteras, incluidos los guardias de costas en la medida en que lleven a cabo tareas de control fronterizo ${ }^{4}$. Con ocasión de la puesta en marcha de la GEFC, el comisario de Migración, Asuntos de Interior y Ciudadanía, Dimitris Avramopoulos, declaró el 6 de octubre de 2016 que «en menos de un año, hemos creado un verdadero sistema europeo de guardia de fronteras y costas, haciendo realidad los principios de responsabilidad y solidaridad compartidas entre los Estados miembros y la Unión”. Sin embargo, esta afirmación no se corresponde con la realidad. El establecimiento de la GEFC y la transformación de Frontex en la Agencia Europea de la Guardia de Fronteras y Costas (en lo sucesivo, la Agencia) no supone realmente crear una verdadera Guardia Europea de Fronteras que venga a reemplazar a los guardias nacionales encargados de la gestión de las fronteras. Al contrario: en el Reglamento de creación de la GEFC se reitera constantemente que la responsabilidad principal en la gestión de las fronteras exteriores corresponde a los Estados miembros ${ }^{6}$. Por esta razón, a primera vista no se comprende bien el contenido del art. 1 del Reglamento, que prevé que "se crea una Guardia Europea de Fronteras y Costas con el objetivo de garantizar una gestión integrada de las fronteras europeas exteriores [...]». Esta ambigüedad y falta de claridad tiene su reflejo en numerosas disposiciones del Reglamento, tal y como se expondrá en el presente estudio.

La unificación bajo el paraguas de la GEFC de la Agencia Frontex y de las autoridades nacionales de los Estados miembro responsables de la gestión de las fronteras constituye en palabras de Bruycker (2016: 564) «a legal fiction». Como han señalado Carrera y Den Hertog (2016: 1), el cambio supone más bien transformar la Agencia Frontex en una "Frontex+». Los cambios introducidos en la configuración de la Agencia no se podrían calificar de revolución, sino más bien de evolución natural en el proceso que se inició en 2004 con la creación de Frontex. Probablemente, la implementación del Reglamento 2016/1624 generará nuevos desarrollos en la gestión de las fronteras en el futuro a medida que surjan nuevos desafíos en este ámbito. Esta evolución se enmarca en el proceso de "agencification" que ha experimentado el Espacio de Libertad, Seguridad y Justicia (ELSJ) en los últimos años. El desarrollo del ELSJ ha conllevado una multiplicación de las actividades desarrolladas por las

\footnotetext{
4 Art. 3 del Reglamento 2016/1624, loc. cit., supra nota 3.

5 «Garantizar la seguridad de las fronteras exteriores de Europa Puesta en marcha de la Agencia Europea de la Guardia de Fronteras y Costas», Comunicado de Prensa 555/16, 6 de octubre de 2016.

6 Preámbulo 6 y art. 5 del Reglamento 2016/1624, loc. cit., supra nota 3.
} 
agencias, las cuales fueron creadas con el objetivo de reforzar la cooperación operativa entre las autoridades nacionales (Santos Vara, 2018: 445; Chamon, 2015; Santos Vara, 2015: 115).

En 2001, la Comisión planteó examinar la necesidad y viabilidad de crear una guardia europea de fronteras ${ }^{7}$. Esta iniciativa se materializó en el Feasibility Study for the Setting-up of a European Border Police de 2002, en el que se defendía la creación de un modelo en red para coordinar y asistir a las autoridades nacionales en la vigilancia y gestión de las fronteras ${ }^{8}$ (Monar, 2006: 197). El siguiente hito en este proceso vendría determinado por la Comunicación de la Comisión de 2002, titulada «Hacia una gestión integrada de las fronteras exteriores de los Estados miembros de la Unión Europea», que daría lugar a la creación de un órgano común de fronteras exteriores con el objetivo de mejorar la coordinación entre los servicios nacionales encargados de la gestión de las fronteras exteriores ${ }^{9}$. Ante los insatisfactorios resultados logrados a través de este órgano de naturaleza intergubernamental, la Comisión propuso en 2003 la creación de la Agencia Frontex ${ }^{10}$, siendo adoptado el Reglamento fundacional de la Agencia en Octubre de $2004^{11}$. Frontex se creó para apoyar a los Estados miembros y promover una gestión más integrada y eficiente de la gestión de las fronteras. Los recursos y las funciones conferidas a Frontex se han expandido en los últimos años en aras de reforzar las fronteras exteriores de la UE, sin que se haya procedido a una transferencia de poderes ejecutivos (Rijpma, 2016a). En 2007 se crearon los equipos de intervención rápida en las fronteras ${ }^{12}$, y en 2011

7 Comunicación de la Comisión al Consejo y al Parlamento Europeo relativa a una Política Común de Inmigración Ilegal, COM (2001) 672 final (15 de noviembre de 2001, p. 18).

8 Feasibility Study for the Setting-up of a European Border Police, Roma, 2002, disponible en: http://cmr.jur.ru.nl/cmr/docs/61.pdf (consultado el 28 de junio de 2017).

9 Comunicación de la Comisión al Consejo y al Parlamento Europeo, Hacia una gestión integrada de las fronteras exteriores de los Estados miembros de la Unión Europea, COM (2002) 233 final, 2002.

10 Comunicación de la Comisión al Parlamento Europeo y al Consejo con vistas al Consejo europeo de Tesalónica relativa al desarrollo de una política común en materia de inmigración ilegal, trata de seres humanos, fronteras exteriores y retorno de residentes ilegales, COM (2003) 323 final (3 de junio de 2003, pp. 7-8).

11 Reglamento 2007/2004 del Consejo de 26 de octubre de 2004 por el que se crea una Agencia Europea para la gestión de la cooperación operativa en las fronteras exteriores de los Estados miembros de la Unión Europea (DO L 349, 25 de noviembre 2004, p. 1).

12 Reglamento (CE) n ${ }^{\circ}$ 863/2007 del Parlamento Europeo y del Consejo, de 11 de julio de 2007, por el que se establece un mecanismo para la creación de equipos de intervención rápida en las fronteras (DO L 199, 31 de julio de 2007, p. 30). 
se introdujeron modificaciones significativas en el Reglamento fundacional de Frontex ${ }^{13}$. En el art. 33.2 bis del Reglamento de Frontex, introducido por la reforma de 2011, se preveía que en la primera evaluación tras la entrada en vigor del Reglamento 1168/2011 se analizará la necesidad de lograr una mayor coordinación de la gestión de las fronteras exteriores de los Estados miembros, incluida la viabilidad de la creación de un sistema europeo de guardias de fronteras $^{14}$. La consultora encargada de llevar a cabo el estudio propuso en 2014 la creación de un sistema europeo de guardias de fronteras basado en tres fases ${ }^{15}$.

En el presente trabajo se analizarán las principales novedades introducidas por el Reglamento de la GEFC con el objetivo de determinar si se han superado las limitaciones que ha presentado en el pasado el mandato de Frontex $y$, por ende, si la UE se ha dotado de los instrumentos necesarios para hacer frente a los desafíos que se planteen en la gestión de las fronteras exteriores en los próximos años. A tales efectos, se prestará especial atención al proceso de implementación del Reglamento en los primeros meses de vigencia del mismo. Tanto la Agencia como la Comisión y los Estados miembros han realizado un significativo esfuerzo para poner en marcha los principales cambios introducidos por el Reglamento en los últimos meses.

\section{EL CONCEPTO DE GESTIÓN INTEGRADA DE LAS FRONTERAS}

Son numerosas las previsiones incluidas en el Reglamento 2016/1624 con el objetivo de reforzar las atribuciones de la Agencia en materia de gestión de fronteras, tal y como se pondrá de manifiesto en el presente trabajo. El Reglamento aumenta sustancialmente las funciones operativas de la Agencia e introduce la función de supervisar la gestión de las fronteras exteriores por

13 Reglamento 1168/2011 del Parlamento Europeo y del Consejo de 25 de octubre de 2011 que modifica el Reglamento (CE) 2007/2004 del Consejo, por el que se crea una Agencia Europea para la gestión de la cooperación operativa en las fronteras exteriores de los Estados miembros de la Unión Europea (DO L 304, de 22 de noviembre de 2011, p. 1).

14 Tanto en el Programa de La Haya como en el de Estocolmo, adoptados por el Consejo Europeo, se preveía que se analizase la posibilidad de crear un sistema europeo de guardias de fronteras. Véase El Programa de la Haya: Consolidación de la libertad, la seguridad y la justicia en la Unión Europea (DO C 53, 3 de marzo de 2005, p. 6); y Programa de Estocolmo: una Europa abierta y segura que sirva y proteja al ciudadano, (4 de mayo de 2010, p. 26).

15 UNISYS, Study on the feasibility of the creation of a European System of Border Guards to control the external borders of the Union, 2014. 
parte de las autoridades nacionales. En este sentido, a la Agencia le corresponde establecer «una estrategia operativa y técnica para la gestión integrada de las fronteras europeas ${ }^{16}$. Las estrategias nacionales para la gestión integrada de las fronteras que han de elaborar las autoridades nacionales deberán ser "coherentes» con la estrategia europea. De este modo, en el nuevo Reglamento se establece una relación de jerarquía entre la Agencia y las autoridades nacionales encargadas de la gestión de las fronteras (De Bruycker, 2016: 561). La Agencia no será simplemente «a central knot and information hub, but also a primus inter pares» (Rijpma, 2016b: 26). En palabras de Peers, la nueva Agencia Frontex «will become the line manager or even the Chief Executive Officer» de las autoridades nacionales encargadas de la gestión de las fronteras. Por lo tanto, la creación de la GEFC viene acompañada de un reforzamiento de los poderes de la Agencia sobre los Estados miembros (Peers, 2015).

Antes de adentrarse en el examen minucioso de las nuevas funciones atribuidas a la Agencia es preciso analizar el concepto de gestión europea integrada de fronteras, que viene a desarrollar por primera vez en una norma de carácter vinculante la previsión contenida en el art. 77.2 (d) del TFUE. Si bien el concepto de gestión integrada de las fronteras europeas, incluido en el Reglamento, amplía sustancialmente las funciones de la Agencia, no es un concepto que aparezca ex novo. La gestión europea integrada de las fronteras se definió por primera vez en las Conclusiones del Consejo Europeo de 4 y 5 de diciembre de 2006 prestando atención a la dimensión material de la gestión de las fronteras. El concepto de gestión integrada de fronteras «is not only about where border controls take place but more about the functions and scope of those controls» (De Bruycker, 2016: 563). La gestión integrada de las fronteras europeas se basa en un modelo de acceso de cuatro niveles, que incluye medidas en terceros países (por ejemplo, en el marco de la política común de visados), medidas en los países vecinos, medidas de control de las fronteras exteriores, así como medidas adoptadas dentro de la zona Schengen, incluido el retorno ${ }^{17}$.

El art. 4 del Reglamento de la GEFC incluye once componentes dentro del concepto de gestión europea integrada de las fronteras europeas, incluyendo los siguientes elementos: control fronterizo, búsqueda y salvamento de personas en peligro en el mar, análisis de riesgos, cooperación entre los Estados miembros y entre las agencias de la UE, la cooperación con terceros países, un mecanismo de control de la calidad para garantizar la aplicación de la legislación europea y mecanismos de solidaridad, en particular los

16 Art. 3 del Reglamento 2016/1624, loc. cit., supra nota 3.

17 Véase el apdo. 3 del preámbulo del Reglamento 2016/1624, loc. cit., supra nota 3. 
instrumentos de financiación de la Unión. Esta larga lista incluye una serie de materias que las autoridades de los Estados miembros responsables de la gestión de las fronteras y la Agencia deberán gestionar de manera integrada, con la excepción del ámbito aduanero, tal y como se refleja claramente en el preámbulo del Reglamento de la GEFC. Sin embargo, las funciones encomendadas a la nueva Agencia en el art. 8 del Reglamento no reflejan todos los elementos incluidos en el concepto de gestión europea integrada de las fronteras y, en particular, no se atribuye ninguna tarea en relación con la seguridad interior (Rijpma 2016b: 14). Esta incoherencia es evidente si se tiene en cuenta que la creación de la GEFC responde no solo al objetivo de gestionar eficazmente el cruce de las fronteras exteriores, sino también a la necesidad de combatir las formas graves de delincuencia con dimensión transfronteriza en aras de lograr un nivel elevado de seguridad interior, respetando plenamente los derechos fundamentales ${ }^{18}$.

A la luz de la amplitud y falta de precisión de los elementos incluidos en el concepto de gestión integrada de fronteras, es preciso que sean objeto de desarrollos ulteriores, tal y como se prevé en el propio Reglamento. La Comisión está liderando el proceso de desarrollo de la estrategia europea de gestión integrada de las fronteras, si bien en el articulado del Reglamento esta tarea se ha atribuido expresamente a la propia Agencia ${ }^{19}$. Está previsto que la Comisión desarrolle el marco político del concepto de gestión europea integrada de las fronteras a través de una comunicación dirigida al Parlamento y al Consejo ${ }^{20}$. Una vez que se hayan adoptado los principales elementos del marco político, la Agencia procederá a establecer «la estrategia operativa y técnica para la gestión integrada de las fronteras europeas», teniendo en cuenta la situación específica de los Estados miembro, en particular su ubicación geográfica ${ }^{21}$. Por último, los Estados miembros deberán proceder a adaptar sus respectivas estrategias, que han de ser coherentes con el marco político establecido por las

18 Art. 1 del Reglamento 2016/1624, loc. cit., supra nota 3.

19 Tan solo en el apdo. 7 del preámbulo se señala que «la elaboración de la política y de la legislación en materia de control de las fronteras exteriores y de retorno, incluido el desarrollo de una estrategia europea de gestión integrada de las fronteras, sigue siendo responsabilidad de las instituciones de la Unión».

20 Tercer Informe de la Comisión al Parlamento Europeo, al Consejo Europeo y al Consejo sobre la puesta en marcha de la Guardia Europea de Fronteras y Costas, $\operatorname{COM}(2017) 219$ final (2 de mayo de 2017).

21 Art. 3 del Reglamento 2016/1624, loc. cit., supra nota 3. Véase Fifth Report from the Commission to the European Parliament, the European Council and the Council on the operationalisation of the European Border and Coast Guard, COM(2017) 467 final (6 de octubre de 2017). 
instituciones y con la estrategia establecida por la Agencia. El objetivo final es que los diversos componentes que integran la gestión de las fronteras europeas se implementen de forma más eficiente y coordinada en la práctica.

\section{LA IMPLEMENTACIÓN DE LOS NUEVOS PODERES DE LA AGENCIA EUROPEA DE LA GEFC}

\section{LA EVALUACIÓN DE VULNERABILIDAD}

Mediante la valoración de vulnerabilidad se pretende que la Agencia pueda evaluar la capacidad y la preparación de los Estados miembros para hacer frente a los retos emergentes en las fronteras exteriores y las posibles repercusiones para el funcionamiento del espacio Schengen ${ }^{22}$. De este modo, se pretende identificar con antelación las debilidades operacionales que presentan los Estados miembros en la gestión de las fronteras y estar en condiciones de responder ante cualquier cambio rápido de las circunstancias (Rijpma 2016b: 14). En el Reglamento de la GEFC se prevé que la valoración de vulnerabilidad sea distinta y complementaria del mecanismo de evaluación de Schengen ${ }^{23}$. La Comisión considera que mientras el mecanismo de evaluación de Schengen es de carácter político, la valoración de vulnerabilidad tiene un carácter meramente técnico. Esta consideración supone ignorar las consecuencias de carácter político que se pueden derivar de la valoración de vulnerabilidad, tal y como se expondrá a continuación (Rijpma 2016b: 14). La nítida diferenciación establecida entre el mecanismo de evaluación de Schengen y la valoración de vulnerabilidad no se percibe en la implementación de ambos instrumentos. En la práctica se está tratando de buscar sinergias y complementariedades entre ambos mecanismos con el objetivo de mejorar el funcionamiento de Schengen ${ }^{24}$.

En el caso de que se identifiquen vulnerabilidades en un determinado Estado miembro para gestionar sus fronteras exteriores, el director ejecutivo de la Agencia ha de realizar una recomendación en la que se identifiquen las medidas necesarias para hacerles frente, así como el plazo para aplicarlas ${ }^{25}$. Si el Estado miembro en cuestión no aplica «las medidas correctivas», recomendadas por el director de la Agencia, el asunto se remitirá al Consejo de

\footnotetext{
Arts. 8, 11 y 13 del Reglamento 2016/1624, loc. cit., supra nota 3.

Art. 12.3 del Reglamento 2016/1624, loc. cit., supra nota 3.

Véase COM(2017) 467 final, loc. cit., supra nota 21.

Art. 13.6 del Reglamento 2016/1624, loc. cit., supra nota 3.
} 
Administración de la Agencia, que determinará mediante una decisión vinculante las medidas que deberá adoptar el Estado miembro implicado para superar la situación de vulnerabilidad en una determinada frontera ${ }^{26}$. Por último, la negativa de un Estado miembro a actuar para hacer frente a una situación de vulnerabilidad, puede conducir a que la Comisión inicie el procedimiento previsto en el art. 19 Reglamento de la GEFC relativo al denominado «derecho a intervenir» por parte de la Agencia.

Las evaluaciones de vulnerabilidad constituyen una de las novedades introducidas por el Reglamento de la GEFC que se han implementado con mayor rapidez desde su entrada en vigor. En julio de 2017, sobre la base de los informes de evaluación de base, el director de Frontex formuló por primera vez una serie de recomendaciones dirigidas a veintiún Estados miembros en las que se proponen medidas específicas para hacer frente a las vulnerabilidades más urgentes que se plantean en las fronteras exteriores ${ }^{27}$. Las evaluaciones de vulnerabilidad se basan en la metodología común adoptada a finales de 2016 y está previsto llevar a cabo en el futuro una evaluación anual de todos los Estados Schengen. Para poder llevar a cabo las evaluaciones de vulnerabilidad es esencial que los Estados proporcionen a la Agencia datos exhaustivos sobre las capacidades existentes. A pesar de algunas dificultades iniciales, a mediados de 2017 los Estados habían proporcionado a la Agencia la información necesaria. La información que proporcionen los funcionarios de enlace de la Agencia desplegados en los Estados miembros puede tener una gran relevancia para llevar a cabo de forma eficaz la valoración de vulnerabilidad. En función del análisis de riesgos, la Agencia puede desplegar funcionarios de enlace en los Estados miembros con el objetivo de garantizar un seguimiento regular de la gestión de las fronteras exteriores ${ }^{28}$. A los funcionarios de enlace corresponde, entre otras tareas, facilitar la cooperación y el diálogo entre la Agencia y las autoridades nacionales responsables de la gestión de las fronteras ${ }^{29}$. La eventual expansión de las funciones y competencias de los funcionarios de enlace

26 Art. 13.7 del Reglamento 2016/1624, loc. cit., supra nota 3.

27 Cuarto Informe de la Comisión al Parlamento Europeo, al Consejo Europeo y al Consejo sobre la puesta en marcha de la Guardia Europea de Fronteras y Costas, $\operatorname{COM}(2017) 325$ (13 de junio de 2017).

28 Varias disposiciones del Reglamento refuerzan las atribuciones de los funcionarios de enlace. Véanse los arts. 8, 12 y 62 del Reglamento 2016/1624, loc. cit., supra nota 3.

29 Los funcionarios de enlace han informar regularmente al director ejecutivo «sobre la capacidad de los Estados miembros para gestionar de manera efectiva la situación en las fronteras exteriores». Véase el art. 12.3 h) del Reglamento 2016/1624, loc. cit., supra nota 3 . 
podría conducir a difuminar en la práctica las responsabilidades respectivas de los Estados miembros y de la Agencia.

A la luz de los resultados obtenidos en las evaluaciones de vulnerabilidad, la Agencia ha identificado seis Estados miembros en relación con los cuales la Agencia se propone llevar a cabo en los próximos meses los denominados «ejercicios de simulación» a fin de probar las respectivas capacidades para hacer frente a los futuros retos en las fronteras exteriores. Igualmente, desde abril de 2017, la Agencia viene realizando la denominada «Evaluación de Amenazas Emergentes» con respecto a Grecia, Italia y España a fin de examinar sus capacidades para hacer frente a amenazas emergentes. Tanto los ejercicios de simulación como la Evaluación de Amenazas Emergentes constituyen desarrollos de la evaluación de vulnerabilidad que no estaban expresamente previstos en el Reglamento de la GEFC.

\section{EL ESTABLECIMIENTO DE LOS CONTINGENTES DE REACCIÓN RÁPIDA}

Los Estados no siempre se han mostrado dispuestos a cooperar con la Agencia poniendo a su disposición los recursos humanos y técnicos que necesita para realizar sus operaciones conjuntas. El Reglamento de la GEFC trata de hacer frente a este déficit estructural que ha caracterizado a la Agencia desde su creación. Una de las novedades más relevantes que introduce el nuevo marco jurídico es la creación del Contingente de Reacción Rápida, que será «un cuerpo permanente a disposición inmediata de la Agencia» que se podrá desplegar en cualquier Estado miembro en un plazo de cinco días hábiles desde el momento en que el director ejecutivo y el Estado miembro de acogida acuerden el plan operativo ${ }^{30}$. Está previsto que el Contingente de Intervención Rápida disponga de un mínimo de 1500 guardias de fronteras u otro personal competente que deberán ponerse a disposición de la Agencia para su despliegue en cuanto lo solicite. Mientras que en el pasado los Estados miembros podían negarse a poner a disposición de la Agencia guardias de fronteras en el caso de que se enfrentaran «a una situación excepcional que afecte de manera sustancial a la ejecución de funciones nacionales»" ${ }^{31}$, el Reglamento 2016/1624 crea una obligación incondicional de ponerlos a disposición de la

30 Art. 20.5 del Reglamento 2016/1624, loc. cit., supra nota 3.

31 La contribución de los Estados miembros, en lo que se refiere a sus agentes de la guardia de fronteras, a operaciones conjuntas y proyectos piloto específicos para el año siguiente se planificará sobre la base de negociaciones y acuerdos bilaterales anuales entre la Agencia y los Estados miembros (art. 3ter del Reglamento 1168/2011, loc. cit., supra nota 13). 
Agencia en el marco de las intervenciones fronterizas rápidas. En todo caso, la contribución de un Estado al contingente de intervención rápida se reducirá a la mitad en el caso de que un análisis de riesgos o el examen de vulnerabilidad ponga de manifiesto que «un Estado se encuentra ante una situación que podría afectar de manera sustancial a la ejecución de sus funciones nacionales» ${ }^{32}$. En cambio, en el contexto de las clásicas operaciones conjuntas, los Estados miembros podrán seguir invocando «una situación excepcional que afecte de manera sustancial a la ejecución de funciones nacionales»" ${ }^{33}$. Igualmente, se prevé que cuando resulte necesario los equipos del Contingente de Intervención Rápida se complementarán con equipos adicionales aportados por los Estados miembros. En este caso se mantiene la posibilidad de alegar por parte de los Estados miembros que se enfrentan a una situación excepcional que les impide aportar más guardias de fronteras ${ }^{34}$.

La Agencia Frontex ha experimentado también dificultades en el pasado para conseguir los equipos técnicos necesarios para llevar a cabo sus operaciones. Para hacer frente a esta dificultad en el Reglamento de la GEFC se desarrollan con más detalle que en el antiguo Reglamento de Frontex las normas relativas al despliegue de equipos técnicos. El contingente de equipos técnicos contendrá los equipos técnicos mínimos que considere necesarios la Agencia, desglosados por tipo de equipos técnicos de forma anual ${ }^{35}$. La contribución de los Estados miembros al contingente de los equipos técnicos se determinará de forma bilateral entre la Agencia y los Estados miembros. Los Estados miembros seguirán disponiendo de la posibilidad de alegar «que se enfrenten a una situación excepcional que afecte de manera sustancial al desempeño de funciones nacionales» ${ }^{36}$. Además, el Reglamento de la GEFC regula detalladamente la posibilidad de que la Agencia arriende o adquiera, por sí sola o en

32 Art. 20. 7 del Reglamento 2016/1624, loc. cit., supra nota 3. El anexo I establece las contribuciones de los Estados miembros al Contingente de Intervención Rápida basadas en compromisos a la luz de las circunstancias existentes en el momento de entrada en vigor del presente Reglamento. En la propuesta de la Comisión se señalaba que cada Estado miembro estaba obligado a poner a disposición de la Agencia guardias de fronteras por un número equivalente a un mínimo del $3 \%$ del personal de los Estados sin fronteras terrestres o marítimas y al $2 \%$ del personal de los Estados miembros con fronteras terrestres o marítimas hasta alcanzar la cifra de al menos 1500 guardias de fronteras. Véase $\operatorname{COM(2015)~} 671$ final, loc. cit., supra nota 3. Esta previsión no fue incluida en la versión final del Reglamento 2016/1624, loc. cit., supra nota 3.

Art. 20.3 del Reglamento 2016/1624, loc. cit., supra nota 3.

34 Art. 39.7 del Reglamento 2016/1624, loc. cit., supra nota 3.

35 Art. 39.8 del Reglamento 2016/1624, loc. cit., supra nota 3.

36

Ibid. 
régimen de copropiedad con los Estados miembros, equipos técnicos ${ }^{37}$. En el caso de que la Agencia adquiera aviones o buques deberán estar registrados en un Estado miembro de conformidad con su legislación nacional. Los Estados miembros están obligados a poner a disposición de la Agencia, en cualquier momento, los equipos técnicos que sean propiedad exclusiva de la Agencia. En cambio, en el caso de equipos adquiridos en régimen de copropiedad, se deberán especificar en el acuerdo bilateral los períodos de plena disponibilidad de los activos por parte de la Agencia. La adquisición de equipos en régimen de copropiedad plantea problemas muy complejos en relación con el régimen jurídico aplicable y los eventuales problemas de responsabilidad que puedan surgir en la práctica (Rijpma 2016b: 18). Sin embargo, no es previsible que la Agencia adquiera sus propios vehículos, barcos y buques en un futuro inmediato.

El establecimiento de un contingente de 1500 guardias de fronteras no parece que sea suficiente para hacer frente a los retos a los que se enfrenta la UE, en particular en el Mediterráneo central. Además, la Agencia está experimentado dificultades para lograr la plena disponibilidad de los guardias de fronteras que forman parte del contingente de reacción rápida, a pesar de que ambos contingentes fueron formalmente establecidos el 7 de diciembre de $2016^{38}$. La mayoría de los Estados miembros siguen siendo reacios a proporcionar los nombres de los agentes correspondientes a sus contribuciones previstas, lo cual impide que la Agencia pueda comprobar si los nombres de los guardias de fronteras designados corresponden a los perfiles exigidos ${ }^{39}$. Igualmente, la Agencia sigue sufriendo carencias importantes para disponer

37 Art. 38 del Reglamento 2016/1624, loc. cit., supra nota 3. Desde la modificación introducida por el Reglamento de 2007, Frontex podía adquirir equipos técnicos, pero no se ha hecho uso de esta posibilidad (art. 7 del Reglamento ${ }^{\circ}$ 863/2007, loc. cit., supra nota 12).

38 Primer Informe de la Comisión al Parlamento Europeo, al Consejo Europeo y al Consejo sobre la puesta en marcha de la Guardia Europea de Fronteras y Costas, COM(2017) 42 final (25 de enero de 2017). Para hacer un seguimiento de esta cuestión, se pueden consultar los sucesivos informes periódicos que ha ido publicando la Comisión sobre la puesta en marcha de la GEFC: Segundo Informe de la Comisión al Parlamento Europeo, al Consejo Europeo y al Consejo sobre la puesta en marcha de la Guardia Europea de Fronteras y Costas, COM(2017) 201 final (2 de marzo de 2017); COM(2017) 219 final, loc. cit., supra nota 20; COM(2017) 325 final, loc. cit., supra nota 27.

$39 \operatorname{COM}(2017) 325$ final, loc. cit., supra nota 27. 
de los equipos técnicos necesarios para dotar de plena operatividad al contingente de equipos de reacción rápida ${ }^{40}$.

\section{EL DENOMINADO «DERECHO A INTERVENIR»}

El Reglamento 2016/1624 incluye la posibilidad de que la Agencia intervenga cuando concurran situaciones en las fronteras exteriores que requieran medidas urgentes. Esta situación concurriría cuando un Estado miembro no haya implementado «las medidas correctivas» exigidas por el Consejo de Administración de la Agencia para hacer frente a una situación de vulnerabilidad en la gestión de las fronteras o «en caso de que exista una presión migratoria desproporcionada que haga que el control de las fronteras exteriores resulte tan inefectivo que ponga en peligro el funcionamiento del espacio Schengen" y no solicite ayuda ${ }^{41}$. La decisión de intervenir para hacer frente a una situación en la que un Estado miembro no es capaz de gestionar sus fronteras constituye una de las novedades más importantes incluidas en el Reglamento de la GEFC.

La sustitución de las autoridades nacionales por la Agencia en la gestión de una determinada frontera plantea cuestiones políticas y jurídicas de gran complejidad. La generalidad de la doctrina ha considerado que el denominado «derecho a intervenir» sin contar con el consentimiento del Estado miembro afectado plantea serias dificultades desde la perspectiva del derecho de la UE (Rijpma 2016b: 18; De Bruycker, 2016: 566; Peers, 2015: 2). El art. 4.2 del TUE prevé que «la seguridad nacional seguirá siendo responsabilidad exclusiva de cada Estado miembro" y el art. 72 del TFUE determina que el título V del Tratado, dedicado al ELSJ, «se entenderá sin perjuicio del ejercicio de las responsabilidades que incumben a los Estados miembros en cuanto al mantenimiento del orden público y la salvaguardia de la seguridad interior». La competencia exclusiva de los Estados miembros para adoptar medidas de carácter coercitivo para salvaguardar la seguridad nacional aparece corroborada por otras disposiciones del TFUE. Los arts. 85.2 y 88.3 del TFUE prohíben que la Agencia Europol aplique medidas coercitivas y excluye la posibilidad de que Eurojust lleve a cabo actos formales de carácter procesal. No parece coherente considerar que mientras que las agencias Europol y Eurojust tienen vedada expresamente la posibilidad de intervenir en ámbitos de competencia

40 Véase $\operatorname{COM}(2017) 467$ final, loc. cit., supra nota 24.

41 Art. 19.1 del Reglamento 2016/1624, loc. cit., supra nota 3. 
exclusiva del Estado, la nueva Agencia pueda intervenir sin el consentimiento del Estado implicado ${ }^{42}$.

Asimismo, el Tribunal de Justicia determinó en la sentencia Meroni que las instituciones tienen serias limitaciones a la hora de delegar el ejercicio de poderes que impliquen una amplia libertad de apreciación a las agencias u órganos de la UE ${ }^{43}$. Si bien se puede considerar que el Tribunal de Justicia limitó los efectos de la jurisprudencia Meroni en la sentencia C-270/12 relativa a los poderes de intervención conferidos a la Autoridad Europea de Valores y Mercados en circunstancias excepcionales, no supone que las instituciones dispongan de libertad absoluta a la hora de delegar la gestión de las fronteras a la Agencia ${ }^{44}$. La gestión de las fronteras implica el desarrollo de actividades que conllevan un cierto grado de discrecionalidad. Por ello, las limitaciones derivadas de la doctrina Meroni, tales como establecer una delimitación precisa de los poderes así como un mecanismo de revisión judicial, siguen resultando aplicables (Rijpma 2016b: 26). El procedimiento previsto en el art. 19 del Reglamento 2016/1624 podría conducir a que la Agencia sustituyera a las autoridades nacionales en la gestión de las fronteras. En la propuesta inicial del Reglamento correspondía a la Comisión adoptar una decisión en forma de acto de ejecución en el que se fijarían las medidas que debería adoptar la Agencia. Varios Estados miembros rechazaron la propuesta de la Comisión al considerarla una violación flagrante de su soberanía (Rosenfeldt, 2016). Como consecuencia de esta oposición, el mecanismo de sustitución fue modificado significativamente, de modo que la decisión de intervenir en un Estado miembro ha de ser adoptada por el Consejo por mayoría cualificada ${ }^{45}$. En estas circunstancias, el Consejo solicitará a la Agencia que prepare un plan operativo con el objetivo de organizar intervenciones fronterizas rápidas, desplegar equipos de apoyo a la gestión de la migración en puntos críticos o coordinar operaciones conjuntas. Sin embargo, en el Reglamento no se explica con suficiente precisión las razones por las que el Consejo se reserva el acto de ejecución, lo cual constituye una excepción a la norma general en virtud de la cual los poderes de ejecución son atribuidos a la Comisión.

$42 \mathrm{Al}$ margen de las disposiciones específicas del título V, otros artículos de los tratados confirman que la UE no puede adoptar medidas de carácter coercitivo en contra de la voluntad de un Estado miembro. Así, por ejemplo, la cláusula de solidaridad a favor de un Estado miembro, prevista en el art. 222 del TFUE, solo se puede activar «a petición de sus autoridades políticas».

43 Sentencia de 13 de junio de 1958, MeronilAlta Autoridad, 9/56, Rec. p. 9.

44 Sentencia del TJUE de 22 de enero de 2014, Autoridad Europea de Valores y Mercados, C-270/12, ECLI:EU:C:2014:18.

45 Art. 19.1 del Reglamento 2016/1624, loc. cit., supra nota 3. 
Aun admitiendo que fuera posible intervenir en contra de la voluntad de un determinado Estado para hacer frente a situaciones en las fronteras exteriores que requieran medidas urgentes, en la práctica la cooperación del Estado afectado con la Agencia reviste un importancia fundamental (Carrera y Den Hertog, 2016: 22). El propio Reglamento prevé que el Estado miembro implicado ha de cooperar con la Agencia para lograr «la ejecución práctica de las medidas» adoptadas por el Consejo ${ }^{46}$. La intervención de la Agencia se basará en el plan operativo elaborado por el director ejecutivo y acordado con el Estado miembro implicado ${ }^{47}$. Por lo tanto, la sustitución de las autoridades nacionales por los equipos de la GEFC en un determinado sector de la frontera difícilmente se podría materializar sin la cooperación del Estado afectado en la elaboración y ejecución del plan operativo. Además, desde una perspectiva estrictamente política es difícilmente concebible que el Consejo decida enviar equipos de la GEFC en contra de la voluntad del Estado miembro afectado.

En la propuesta inicial de la Comisión sobre la GEFC no se incluía ningún mecanismo para forzar al Estado miembro implicado a cooperar con las instituciones y la Agencia, lo cual constituía indudablemente una de las debilidades más importantes de la propuesta. En la versión final del Reglamento se ha paliado al menos parcialmente esta deficiencia. Si un Estado miembro no coopera en el proceso de implementación de las medidas adoptadas y no ejecuta la decisión adoptada por el Consejo, se pondrá en marcha un mecanismo similar al previsto en el art. 26 del Código Schengen ${ }^{48}$, de modo que el Consejo puede recomendar el restablecimiento de los controles en las fronteras interiores, lo que podría conducir a su exclusión del espacio Schengen por un período máximo de dos años (Rijpma, 2016b: 26). Al igual que sucede con la evaluación de vulnerabilidad anteriormente examinado, no se puede ignorar que existe el riesgo de que se politice este proceso.

\section{EL DESARROLLO DE LOS HOTSPOTS}

A pesar de que el establecimiento de los denominados hotspots constituye uno de los desarrollos más significativos que han tenido lugar en el marco de la Agenda Europa de Inmigración, su regulación inicial se ha llevado a

46 Art. 19.1 y 3 del Reglamento 2016/1624, loc. cit., supra nota 3.

47 Art. 19.5 del Reglamento 2016/1624, loc. cit., supra nota 3.

48 Véase el art. 29 del Reglamento (UE) 2016/399 del Parlamento Europeo y del Consejo de 9 de marzo de 2016 por el que se establece un Código de normas de la Unión para el cruce de personas por las fronteras (Código de fronteras Schengen) (DO L 77, de 23 de marzo de 2016, p. 1). 
cabo únicamente a través de instrumentos de carácter no vinculante. El 15 de julio de 2017, el comisario Avramopoulos envió al Consejo de Justicia y Asuntos de Interior una "explanatory note» sobre los hotspots ${ }^{49}$, en la que se definen como lugares «characterized by specific and disproportionate migratory pressure, consisting of mixed migratory flows, which are largely linked to the smuggling of migrants, and where the Member State concerned might request support and assistance to better cope with the migratory pressure ${ }^{50}$. Los expertos desplegados en los hotspots colaboran con las administraciones nacionales llevando a cabo una gran variedad de tareas, tales como el registro y la identificación de los inmigrantes y refugiados. Los hotspots constituyen una experiencia totalmente novedosa de cooperación entre agencias de la UE, en particular Frontex, Easo, Europol y otros organismos competentes de la UE. El flujo sin precedentes de inmigrantes a los que han tenido que hacer frente Grecia e Italia llevó al establecimiento de esta suerte de administración europea integrada en la gestión de las políticas de fronteras y asilo en los hotspots (Tsourdi, 2016: 997; Tsourdi, 2017).

El Reglamento de la GEFC tiene el mérito de regular por primera vez en un acto jurídico vinculante los hotspots, que se caracterizan como «una zona en la que el Estado miembro de acogida, la Comisión, los organismos de la Unión competentes y los Estados miembros participantes cooperan con el objeto de gestionar un reto migratorio desproporcionado, existente o potencial, caracterizado por un aumento significativo del número de migrantes que llegan a las fronteras exteriores ${ }^{51}$. Entre las nuevas funciones más relevantes atribuidas a la Agencia se incluye la de asistir a la Comisión en la coordinación de las diferentes agencias que actúan en los hotspots y la de ofrecer asistencia a los Estados miembros en el marco de «los equipos de apoyo a la gestión de la migración en puntos críticos $\aleph^{52}$. Cuando un Estado miembro se enfrenta a un reto migratorio desproporcionado puede solicitar el envío de equipos de apoyo a la gestión de la migración ${ }^{53}$.

49 Explanatory Note on the «Hotspot» approach, disponible en: http://www.statewatch. org/news/2015/jul/eu-com-hotsposts.pdf (consultado el 12 de noviembre de 2017). El contenido de este documento sería desarrollado posteriormente en la Comunicación de 29 de septiembre de 2015 de la Comisión al Parlamento Europeo, al Consejo Europeo, al Consejo y al Parlamento Europeo. Gestión de la crisis de los refugiados: estado de ejecución de las acciones prioritarias con arreglo a la Agenda Europea de Migración, COM(2015) 510 final, 14 de septiembre de 2015.

50 Ibid.

51 Art. 2.10 del Reglamento 2016/1624, loc. cit., supra nota 3.

52 Art. 7 g) del Reglamento 2016/1624, loc. cit., supra nota 3.

53 Art. 18 del Reglamento 2016/1624, loc. cit., supra nota 3. 
Los hotspots están destinados a tener un rol muy relevante en el futuro en la gestión de las crisis migratorias, tal y como es reconocido por el propio Reglamento de la GEFC. Por esta razón, no se comprende bien que la Comisión no haya propuesto un instrumento jurídico específico en el que se regule de forma omnicomprensiva el marco jurídico de los hotspots. Todo parece indicar que la Comisión ha preferido que los hotspots se desarrollen en un marco regulatorio flexible, el cual se adapta mejor a las necesidades prácticas y operacionales. Una de las cuestiones fundamentales que plantea la implicación de las agencias en el proceso de implementación de las normas comunes de asilo y de gestión de fronteras en los hotspots es determinar si pueden ser consideradas responsables por las eventuales vulneraciones de los derechos fundamentales que puedan ocurrir. A pesar de que se ha debatido intensamente si se puede exigir la responsabilidad de Frontex o Easo por eventuales vulneraciones de los derechos fundamentales en los hotspots, no se ha proporcionado aún una respuesta satisfactoria a esta cuestión (Santos Vara, 2018: 454; Neville et al., 2016; Maiani, 2016; Tsourdi, 2016). Si bien los poderes ejecutivos siguen correspondiendo formalmente a los Estados miembros, la intensa participación de las agencias en la implementación de las normas europeas requiere la adopción de un marco regulatorio específico que permita determinar la eventual responsabilidad de los agentes participantes del Estado afectado y de las agencias europeas. Asimismo, el predominio de Frontex en los hotspots puede conducir a prestar más atención al control de fronteras y la lucha contra la criminalidad transfronteriza que a la obligación de proporcionar protección internacional a los refugiados (Rijpma, 2016b: 26).

\section{EL REFUERZO DEL PAPEL DE LA AGENCIA EN MATERIA DE RETORNO}

Desde la creación de Frontex se le ha atribuido la tarea de facilitar a los Estados miembros el apoyo necesario para la organización de operaciones de retorno conjuntas de inmigrantes irregulares ${ }^{54}$. La intervención de Frontex en las operaciones de retorno ha ido adquiriendo cada vez una mayor importancia. En octubre de 2015, el Consejo Europeo solicitó ampliar el mandato de Frontex en relación con el retorno efectivo de los nacionales de terceros países en situación irregular, por ejemplo mediante la organización de operaciones de retorno por iniciativa propia. El logro de unos resultados más eficaces en el retorno de los inmigrantes que no tengan derecho a residir en el territorio de los Estados miembros se ha convertido en un objetivo fundamental de la política de inmigración de la UE. En septiembre de 2015, la Comisión adoptó un

54 Art. 2 fel Reglamento 2007/2004, loc. cit., p. 26, supra nota 11. 
Plan de Acción de la UE en materia de retorno en el que se preveían medidas específicas para mejorar la eficiencia del sistema de retorno de la Unión Europea $^{55}$. Como se reconoce en el Plan de Acción renovado de 2107, las tasas de retorno logradas en los últimos años son insatisfactorias ${ }^{56}$.

La Agencia ha de intensificar la asistencia que proporciona a los Estados miembros para el retorno de nacionales de terceros Estados en situación irregular. Mientras que en el marco del antiguo Reglamento de Frontex cuando dos o más Estados se ponían de acuerdo para llevar a cabo una operación de retorno la Agencia podía prestarles asistencia para la organización de operaciones de retorno conjuntas ${ }^{57}$, el Reglamento de la GEFC refuerza notablemente el papel de la Agencia en materia de retorno mediante la creación de la Oficina de Retorno en el seno de la Agencia ${ }^{58}$. A la Agencia se le encomienda coordinar y organizar operaciones de retorno desde uno o más Estados miembros y promover su organización por iniciativa propia para prestar apoyo operativo a los Estados miembros cuyos sistemas de retorno se encuentran sometidos a una gran presión" ${ }^{59}$. Asimismo, se prevé que si esta situación «supone un reto concreto y desproporcionado para un Estado miembro», la Agencia deberá, a petición de dicho Estado miembro, poner en marcha las denominadas «intervenciones de retorno rápido» ${ }^{60}$. Sin embargo, en el Reglamento de la GEFC no se especifica claramente en qué se diferencian las «intervenciones de retorno rápido" de las operaciones de retorno ordinarias. Es de suponer que la diferencia estriba en la celeridad con la que se proporciona la asistencia

55 Comunicación de la Comisión al Parlamento Europeo y al Consejo. Plan de Acción de la UE en materia de retorno, COM (2015) 453 final (9 de septiembre de 2015).

56 Comunicación de la Comisión al Parlamento Europeo y al Consejo relativa a una política de retorno más eficaz en la Unión europea - Un plan de acción renovado, COM (2017) 200 final (2 de marzo de 2017). En aplicación del Plan de Acción renovado, la Comisión ha publicado una recomendación dirigida a los Estados miembros con el objetivo de mejorar la eficacia en el proceso de expulsión de los extranjeros [Recomendación 2017/432 de la Comisión, de 7 de marzo de 2017, sobre la manera de lograr que los retornos sean más eficaces al aplicar la Directiva 2008/115/CE del Parlamento Europeo y del Consejo, C (2017) 1600].

57 Reglamento 2007/2004, loc. cit., p. 26, supra nota 11.

58 Art. 26 del Reglamento 2016/1624, loc. cit., supra nota 3.

59 Apdo. 34 del preámbulo y art. 27 del Reglamento 2016/1624, loc. cit., supra nota 3. En el contexto de una intervención de retorno, el director ejecutivo ha de elaborar un plan operativo que cuente con el consentimiento del Estado miembro de acogida y los Estados miembros participantes (art. 33 del Reglamento 2016/1624, loc. cit., supra nota 3).

60 Art. 29.3 del Reglamento 2016/1624, loc. cit., supra nota 3. 
técnica y operativa al Estado afectado. Evidentemente, la adopción de las decisiones de retorno corresponde adoptarla a las autoridades nacionales, si bien se trata de una competencia que ha de ejercerse en el marco de lo previsto en la Directiva 2008/11561. Por lo tanto, la Agencia no puede entrar a evaluar los fundamentos en los que se basan las decisiones de retorno.

A tales efectos, a la Agencia se le dotará de tres tipos de agentes, que formarán los equipos europeos de intervención en materia de retorno que se desplegarán durante las operaciones de retorno: supervisores del retorno forzoso, escoltas para retornos forzosos y especialistas de retorno ${ }^{62}$. Los Estados miembros están obligados a facilitar los agentes salvo en caso de que se enfrenten a una situación excepcional que afecte de manera sustancial a la ejecución de funciones nacionales ${ }^{63}$. Antes de su participación en actividades de retorno, los miembros de los equipos de retorno han de haber recibido la formación especializada sobre el derecho de la Unión y el derecho internacional aplicables, en particular en lo que se refiere a los derechos fundamentales y al acceso a la protección internacional ${ }^{64}$. A principios de 2017 se constituyeron formalmente los tres tipos de agentes destinados a prestar apoyo a los Estados miembros en las operaciones de retorno ${ }^{65}$. Si bien todos los Estados miembros han contribuido a al menos uno de los tres

61 Directiva 2008/115 del Parlamento Europeo y del Consejo de 16 de diciembre de 2008 relativa a normas y procedimientos comunes en los Estados miembros para el retorno de los nacionales de terceros países en situación irregular (DO L 348, 24 de diciembre de 2008, p. 98).

62 Arts. 28, 29 y 30 del Reglamento 2016/1624, loc. cit., supra nota 3. El contingente de supervisores para el retorno forzoso es competente para llevar a cabo actividades de control del retorno forzoso en virtud de lo previsto en el art. 8.6 de la Directiva Retorno. El contingente de escoltas para el retorno forzoso se crea a partir de órganos nacionales competentes para que lleven a cabo operaciones de retorno utilizando medidas coercitivas proporcionadas y de conformidad con los derechos fundamentales. El contingente de especialistas de retorno realiza tareas específicas, como la identificación de grupos concretos de extranjeros, obtención de documentos de viajes, así como el apoyo a la cooperación consultar (arts. 30 y 31 del Reglamento 2016/1624, loc. cit., supra nota 3).

63 Arts. 29.3, 30.3 y 31.3 del Reglamento 2016/1624, loc. cit., supra nota 3.

64 Art. 36, Reglamento 2016/1624. Como consecuencia de la situación vulnerable en la que se encuentran los menores de terceros Estados, el Reglamento prevé que todos los contingentes deberán recibir formación especializada en materia de protección de menores (art. 35 Reglamento 2016/1624, loc. cit., supra nota 3).

$65 \operatorname{COM(2017)} 219$ final, loc. cit., supra nota 20; COM(2017) 325 final, loc. cit., supra nota 27. 
contingentes, la Agencia sigue experimentando dificultades para lograr el número de expertos cualificados requerido. Asimismo, la Comisión reconoce que mayoría de los Estados miembros no solicita la ayuda de la Agencia para organizar las operaciones de retorno. Por ello, la Comisión insta a la Agencia que sea más activa para proponer la organización de operaciones de retorno a los Estados miembros ${ }^{66}$.

En el Reglamento de la GEFC se regulan expresamente las denominadas «operaciones de retorno de recogida» en las que el tercer país de retorno proporciona los medios de transporte y los escoltas. En este tipo de operaciones se prevé que durante el desarrollo de la operación estará presente un representante del Estado miembro y un supervisor de retorno con el objetivo de garantizar el respeto de los derechos fundamentales y el empleo proporcionado de la fuerza ${ }^{67}$. Estas operaciones tienen el potencial de multiplicar la capacidad de retorno de la UE de forma poco costosa, por lo que la Agencia debería invertir más en el apoyo a la capacidad de los terceros países para participar en tales operaciones, en particular organizando actividades de formación especializa$\mathrm{das}^{68}$. No parece que sea siempre factible exigir a un agente de un tercer Estado el cumplimiento de estas obligaciones, así como exigir responsabilidad por las eventuales violaciones de los derechos humanos que se produzcan durante el desarrollo de una operación de retorno (Rijpma, 2016b: 21).

En la propuesta inicial de la Comisión se contemplaba también la posibilidad de llevar a cabo «operaciones de retorno mixtas», en las que varios retornados son trasladados desde un tercer país a otro tercer país ${ }^{69}$. Afortunadamente, esta posibilidad no fue incluida en la versión final del Reglamento, pues las "operaciones de retorno mixtas» planteaban aún mayores complicaciones desde la perspectiva de los derechos fundamentales que las «operaciones de retorno de recogida». La posibilidad de llevar a cabo operaciones de retorno mixtas se condicionaba a que el tercer país que emitiera la decisión de retorno estuviera sometido al Convenio Europeo de Derechos Humanos. Sin embargo, existía claramente el riesgo de que los agentes de la Agencia resultaran implicados en operaciones de retorno de inmigrantes entre terceros Estados, en las que no se garantizarán los derechos fundamentales y el empleo proporcionado de los medios de coerción durante toda la operación de devolución.

$66 \operatorname{COM}(2017) 325$ final, loc. cit., supra nota 27.

67 Art. 28.3 del Reglamento 2016/1624, loc. cit., supra nota 3.

$68 \operatorname{COM}(2017) 200$ final, loc. cit., supra nota 56.

69 Art. 27.4, COM (2015) 671 final, loc. cit., supra nota 3. 
Aún no se han clarificado las tareas operativas y las eventuales responsabilidades del personal del contingente que participa en actividades de retorno ${ }^{70}$. Es muy relevante clarificar este tipo de cuestiones en la medida en que en las operaciones de retorno, que normalmente se desarrollan a través del transporte aéreo, no es fácil determinar cuál es el Estado de acogida (Rijpma, 2016b: 28). En estas circunstancias, puede que resulte difícil saber cuáles son las normas aplicables en el caso de que se plantee la responsabilidad penal o civil de los miembros de los equipos europeos de retorno (Rijpma, 2016b: 28). No se trata de una hipótesis remota, ya que las operaciones de retorno pueden implicar el recurso a medidas de carácter coercitivo. La jurisdicción penal debería corresponder al país de la matrícula de la aeronave en aplicación de las previsiones contenidas en el Convenio de Tokio sobre infracciones y ciertos otros actos cometidos a bordo de las aeronaves ${ }^{71}$.

\section{EL REFUERZO DEL MANDATO DE LA AGENCIA PARA EL TRATAMIENTO DE DATOS DE CARÁCTER PERSONAL}

En el marco del régimen jurídico establecido por el antiguo Reglamento de Frontex, la Agencia no solo intercambiaba datos con la Comisión y los Estados miembros, sino que estaba también autorizada a tratar datos recogidos en el marco de las operaciones conjuntas, los proyectos piloto y las intervenciones rápidas con el fin de contribuir a la seguridad de las fronteras exteriores $^{72}$. En particular, se preveía que Frontex podía tratar los datos personales relativos a personas de las que se sospechaba que estaban implicadas en actividades delictivas transfronterizas, en actividades de inmigración ilegal $o$ en actividades de trata de personas ${ }^{73}$.

El Reglamento de la GEFC refuerza de forma notable el mandato de la Agencia para el tratamiento de datos de carácter personal con el objetivo de lograr una aplicación efectiva de la gestión integrada de las fronteras exteriores. La Agencia puede tratar datos de carácter personal recogidos por su propio personal o por los Estados miembros durante el desarrollo de las operaciones conjuntas, los proyectos piloto e intervenciones rápidas, así como

$70 \operatorname{COM(2017)} 325$ final, loc. cit., supra nota 27.

71 Esta es la solución que parece plantearse en el apdo. 39 del preámbulo del Reglamento 2016/1624, loc. cit., supra nota 3.

72 Art. 11. C. 2 del Reglamento 2007/2004, loc. cit., supra nota 11.

73 El Reglamento de la GEFC incluye también el terrorismo (art. 47.1 del Reglamento 2016/1624, loc. cit., supra nota 3). 
en el marco de los equipos de apoyo a la gestión de la migración (hotspots) y de las operaciones de retorno ${ }^{74}$. Asimismo, la Agencia está facultada para transmitir los datos personales a EASO, Europol o Eurojust. El Reglamento de la GEFC autoriza a la Agencia a recoger y tratar una gran cantidad de datos personales relativos a los nacionales de terceros Estados en situación irregular, incluidas personas con derecho a protección internacional. En el marco del régimen jurídico anterior, Frontex no estaba autorizada a tratar datos de inmigrantes en situación irregular. No es de extrañar que el Supervisor Europeo de Protección de Datos (SEPD) señalara, al examinar la propuesta de la Comisión, que el régimen jurídico previsto presenta debilidades importantes en la regulación del tratamiento de datos personales por parte de la Agencia ${ }^{75}$. Por otra parte, el SEPD consideró que en la propuesta no se distinguía claramente entre las diferentes finalidades para las que se procesan los datos. Esta distinción es fundamental porque el marco jurídico aplicable es distinto dependiendo de si la finalidad es la gestión de la inmigración o tipo penal. En el primer caso resulta aplicable el Reglamento 2016/679 y en el segundo, la Directiva 2016/68076.

\section{LA GUARDIA EUROPEA DE COSTAS: UN CONCEPTO GRANDILOCUENTE}

Las autoridades nacionales que llevan a cabo funciones de guardacostas son responsables de una gran variedad de tareas que pueden incluir la seguridad, la protección, la búsqueda y el salvamento marítimos, el control fronterizo, el control de la pesca, el control aduanero, las funciones de policía

74 Arts. 47 y 48 del Reglamento 2016/1624, loc. cit., supra nota 3.

75 Recomendaciones del Supervisor Europeo de Protección de Datos relativas a la propuesta de Reglamento Europeo sobre la Guardia Europea de Fronteras y Costas, 2/2016 (18 de Marzo de 2016).

76 Reglamento 2016/679 del Parlamento y del Consejo de 27 de abril de 2016 relativo a la protección de las personas físicas en lo que respecta al tratamiento de datos personales y a la libre circulación de estos datos y por el que se deroga la Directiva 95/46/ CE (Reglamento general de protección de datos) (DO L 119, 4 de mayo de 2016, p. 1); Directiva 2016/680 del Parlamento y del Consejo de 27 de abril de 2016 relativa a la protección de las personas físicas en lo que respecta al tratamiento de datos personales por parte de las autoridades competentes para fines de prevención, investigación, detección o enjuiciamiento de infracciones penales o de ejecución de sanciones penales, y a la libre circulación de dichos datos y por la que se deroga la Decisión Marco 2008/977/JAI del Consejo (DO L 119, 4 de mayo de 2016, p. 89). 
y seguridad en general y la protección del medio ambiente. En el desarrollo de este conjunto de funciones están implicadas más de trescientas autoridades civiles y militares en el conjunto de los Estados miembros (Vasquez et al., 2014). A su vez intervienen en el desarrollo de las funciones de guardia de costas cuerpos de naturaleza civil, militar y paramilitar dependiendo de los Estados miembros (Carrera et al., 2017: 29). Varias agencias de la UE apoyan también a los Estados miembros en sus actuaciones desarrolladas en estos ámbitos, destacando, sobre todo, la Agencia Europea de Seguridad Marítima (AESM), la Agencia Europea de Control de la Pesca (AECP) y la propia Agencia Frontex.

La crisis derivada de la llegada masiva de inmigrantes y refugiados a Grecia e Italia ha puesto claramente de manifiesto la necesidad de proporcionar una respuesta más coordinada de las agencias pertinentes de la UE y del amplio conjunto de autoridades nacionales que tienen encomendadas tareas de guardacostas en el Mediterráneo ${ }^{77}$. Dado que los guardacostas desempeñan una función de gran relevancia en la protección de las fronteras marítimas y en el salvamento marítimo, es necesario mejorar la coordinación en la práctica entre las autoridades nacionales para lograr resultados más eficientes. Por esta razón, en el nuevo Reglamento se incluye por primera vez el concepto de Guardia Europea de Costas. Las autoridades nacionales de guardacostas forman parte también de la GEFC en la medida en que llevan a cabo operaciones de vigilancia de la frontera marítima ${ }^{78}$. De las once funciones de guardacostas identificadas por el European Coast Guard Functions Forum (ECGFF) a Frontex solo se le atribuye la vigilancia de las fronteras marítimas. Incluso se discutió durante la elaboración del Reglamento 2016/1624 si debía hacerse referencia a la Guardia Europea de Costas en la denominación misma del Reglamento. Fue incluida inicialmente por la Comisión en su propuesta, suprimida posteriormente por el Consejo y finalmente incluida en la versión final del Reglamento 2016/162479. La Guardia Europea de Costas existe únicamente en la denominación del Reglamento 2016/1624, no en la realidad. $\mathrm{Ni}$ siquiera se definen en el texto del propio Reglamento las funciones de

77 Comunicación de la Comisión al Parlamento Europeo y al Consejo, La Guardia Europea de Fronteras y Costas y una gestión eficaz de las fronteras exteriores de Europa, COM (2015) 673 final (15 de diciembre de 2015).

78 Preámbulo, párr. 5 y art. 3 del Reglamento 2016/1624, loc. cit., supra nota 3.

79 Fabrice Leggeri, director ejecutivo de Frontex, señaló con ocasión de la inauguración de la nueva Agencia que «the term "coast guard» was decided to be included in the name as coast guards do often take care of maritime border control functions». 
guardacostas, sino en el preámbulo ${ }^{80}$. Como se expondrá a continuación, no están claras las implicaciones prácticas que se derivan de la inclusión de los guardacostas bajo el paraguas de la GEFC.

El Reglamento expande las competencias de la Agencia para apoyar a las autoridades nacionales en el cumplimiento de sus funciones de guardacostas, no limitándose a las autoridades que lleven a cabo labores de vigilancia de la frontera marítima. Es obvio que se derivan muchas ventajas de una mayor cooperación entre los distintos actores implicados en el medio marino en consonancia con la gestión integrada de las fronteras europeas y las estrategias de seguridad marítima. El art. 53 del Reglamento de la GEFC prevé que la Agencia, la AESM y la AECP han de intensificar su cooperación, tanto entre sí como con las autoridades nacionales que lleven a cabo funciones de guardacostas mediante la puesta en común, la fusión y el análisis de la información de la que dispongan las tres agencias, la prestación de nuevos servicios de vigilancia y comunicación, el desarrollo y la puestas en común de capacidades, el análisis de retos operativos y riesgos emergentes en el ámbito marítimo, así como la planificación y ejecución de operaciones polivalentes. A tales efectos, el mismo día en el que se adoptó el Reglamento de la GEFC se modificaron los reglamentos de la AESM y la AECP con el objetivo de adaptarlos al nuevo mandato de la Agencia ${ }^{81}$. Así, por ejemplo, se dará acceso a la Agencia a la información sobre buques utilizados para la inmigración ilegal que hayan sido detectados en el desarrollo de operaciones marítimas de control de pesca o de detección de vertidos de hidrocarburos ${ }^{82}$. De este modo, se trata de lograr una "cooperación pragmática transectorial» que permita aprovechar los recursos y las capacidades que no están estrictamente vinculadas con el control de las fronteras ${ }^{83}$. El 17 de marzo de 2017, Frontex, la AESM y la AECP han

80 Preámbulo, párr. 44 del Reglamento 2016/1624, loc. cit., supra nota 3. Las funciones mencionadas en el preámbulo se corresponden en gran medida con las identificadas por el ECGFF.

81 Reglamento (UE) 2016/1625 del PE y del Consejo de 14 de septiembre de 2016 que modifica el Reglamento (CE) 1406/2002 por el que se crea la Agencia Europea de Seguridad Marítima (DO L 251, de 16 de septiembre de 2016, p. 77); Reglamento (UE) 2016/1626 del PE y del Consejo de 14 de septiembre de 2016 que modifica el Reglamento (CE) 768/2005 del Consejo por el que se crea la Agencia Comunitaria de Control de la Pesca (DO L 251, de 16 de septiembre de 2016, p. 80).

82 Para un examen del desarrollo de la cooperación entre las tres agencias, véase $\operatorname{COM(2017)~} 201$ final, loc. cit., supra nota 38.

83 COM (2015) 673 final, loc. cit., supra nota 77, pp. 7 y 8. Está previsto el desarrollo de un sistema de aeronaves pilotadas a distancia (RPAS) que permita eliminar el vacío operativo existente entre las imágenes por satélite y las aeronaves de patrulla marítima. 
firmado un Acuerdo Tripartito de Trabajo para definir las modalidades de cooperación entre las tres agencias de conformidad con el nuevo mandato que se les ha encomendado en sus normas fundacionales ${ }^{84}$.

El art. 53 del Reglamento 2016/1624 puede contribuir en la práctica a desarrollar la cooperación entre las tres agencias y a prestar apoyo a las autoridades nacionales que llevan a cabo funciones de guardacostas. Sin embargo, el contenido del art. 53 del Reglamento se caracteriza por su vaguedad y genera varios interrogantes. En primer lugar, el intercambio de información entre agencias que tienen finalidades distintas plantea problemas desde la perspectiva de la protección de datos, aun cuando se prevea que el intercambio se llevará a cabo respetando las respectivas bases jurídicas y sin perjuicio de la titularidad de los datos por parte de los Estados miembros ${ }^{85}$. El intercambio de información entre agencias que tienen mandatos distintos constituye una extensión de sus respectivos mandatos (Rijpma, 2016b: 34). Las disposiciones del Reglamento 2016/1624 dedicadas al intercambio de datos no hacen referencia expresa a la AESM y la AECP ni a la lucha contra las actividades delictivas en el medio marítimo ${ }^{86}$. En segundo lugar, si bien en los reglamentos de las tres agencias figuran disposiciones idénticas al art. 53 del Reglamento 2016/1624, no es fácil determinar cuáles serán sus implicaciones prácticas. Cabe legítimamente plantearse si en el futuro una operación conjunta de la Agencia puede implicarse en actividades que vayan más allá de su mandato o es necesario poner en marcha una operación conjunta en la que participen agentes de las tres agencias. La planificación y ejecución de operaciones polivalentes por parte de las tres agencias pueden quizás contribuir a proporcionar una solución a estos interrogantes.

El RPAS va encaminado a la creación de un servicio conjunto de sistemas de aeronaves pilotadas a distancia a disposición de Frontex, la AESM y la AECP. Véase COM (2017) 201 final, loc. cit., supra nota 38, p. 12.

84 Véase «Frontex, EMSA and EFCA Strengthen Cooperation on Coast Guard Functions», 23 de marzo de 2017, disponible en https:/goo.gl/nFQhLX (consultado el 5 de octubre de 2017). Con anterioridad la AESM y Frontex firmaron un acuerdo de cooperación para mejorar el intercambio de información entre las dos agencias de la UE. En virtud del mismo, la AESM, con el consentimiento de los Estados miembros involucrados, podría facilitar información a Frontex acerca de los datos contenidos en su sistema de supervisión de buques. Véase «European Fisheries Control Agency (EFCA) and Frontex agree on Closer Cooperation», disponible en: https://goo.gl/ qKUV3H (consultado el 5 de octubre de 2017).

86 Ibid. arts. 45 a 50 del Reglamento 2016/1624, loc. cit., supra nota 3. 


\section{LA ATRIBUCIÓN A FRONTEX DE ACTIVIDADES SAR}

En la propuesta original presentada por la Comisión no se incluía, entre las tareas de la Agencia, la intervención en las operaciones de búsqueda y salvamento de personas en peligro en el mar (SAR) que puedan presentarse durante las operaciones de vigilancia de las fronteras marítimas ${ }^{87}$. En la propuesta original se hacía referencia únicamente a la posibilidad de recibir formación en actividades de búsqueda y rescate ${ }^{88}$. La Comisión reconocía que la no atribución a la nueva Agencia de una competencia expresa para realizar operaciones SAR constituía una de sus principales limitaciones ${ }^{89}$. Esta omisión fue corregida durante el desarrollo del procedimiento legislativo, sobre todo gracias a la presión ejercida por el Parlamento Europeo. El reconocimiento de que la Agencia puede prestar apoyo a los Estados miembros y a terceros países en las operaciones SAR viene a reconocer el hecho de que muy a menudo las operaciones de vigilancia marítima se transforman en operaciones $\mathrm{SAR}^{90}$. Tanto en el Reglamento Eurosur como en el Reglamento 656/2014 por el que se establecen normas para la vigilancia de las fronteras marítimas exteriores en el marco de las operaciones de Frontex se habían reconocido con anterioridad esta realidad ${ }^{91}$ (Santos Vara y Sánchez-Tabernero, 2016: 65).

La introducción de normas vinculantes en relación con las operaciones SAR generó una gran controversia en el marco de la negociación del Reglamento 656/2014. Italia, Grecia, Malta, Francia y Chipre alegaron que no era aceptable que se regulasen mediante un acto legislativo las operaciones SAR y de desembarco porque se trata de materias que se enmarcan dentro de la competencia exclusiva de los Estados y que han de ser ejercidas en el marco del derecho internacional. En particular, este grupo de Estados no aceptaban que del Reglamento 656/2014 se derivaran nuevas obligaciones y responsabilidades

\footnotetext{
Art. 7, COM (2015) 671 final, loc. cit., supra nota 3.

Art. 35, COM (2015) 671 final, loc. cit., supra nota 3.

COM (2015) 673 final, loc. cit., supra nota 77, p. 2.

Art. 8 del Reglamento 2016/1624, loc. cit., supra nota 3.

91 Reglamento 1052/2013 del Parlamento Europeo y del Consejo de 22 de octubre de 2013 por el que se crea un Sistema Europeo de Vigilancia de Fronteras (Eurosur) (DO L 295, de 22 de octubre de 2013, p. 11); Reglamento 656/2014 del Parlamento y del Consejo de 15 de mayo de 2014 por el que se establecen normas para la vigilancia de las fronteras marítimas exteriores en el marco de la cooperación operativa coordinada por la Agencia Europea para la Gestión de la Cooperación Operativa en las Fronteras Exteriores de los Estados miembros de la Unión Europea (DO L 189, de 27 de junio de 2014, p. 93).
} 
cuando se presentan situaciones $\mathrm{SAR}^{92}$. En su opinión, esta cuestión debía ser únicamente regulada en el plan operativo de cada una de las operaciones y no en el texto del propio Reglamento 656/2014. Finalmente, este grupo de Estados retiró su oposición a la inclusión de normas SAR y de desembarco en el Reglamento 656/2014 cuando se les garantizó que no resultarían aplicables a las operaciones nacionales, tales como «Mare Nostrum», desarrollada por Italia en el Mediterráneo. De este modo, el Reglamento 656/2014 no debe afectar a las obligaciones internacionales de los Estados miembros aplicables a las operaciones $\mathrm{SAR}^{93}$.

El Reglamento de la GEFC introduce una mejora sustancial en este ámbito al incluir las operaciones SAR dentro del concepto de gestión europea integrada de las fronteras y reconocer expresamente que una de las funciones de la Agencia es la de "prestar ayuda técnica y operativa a los Estados miembros y a terceros países [...] para apoyar las operaciones de búsqueda y salvamento de personas en peligro en el mar que puedan presentarse durante las operaciones de vigilancia de las fronteras marítimas» ${ }^{94}$. Es preciso señalar que la Agencia no dispone de un poder que pueda ejercer de forma autónoma respecto de las autoridades nacionales, sino que su función consiste en prestar apoyo a las autoridades nacionales. En este sentido, se prevé expresamente que la aplicación del Reglamento de la GEFC no afecta al reparto de competencias entre la Unión y los Estados miembros en virtud de los tratados, ni a las obligaciones internacionales que incumben a los Estados miembros en relación con las operaciones $\mathrm{SAR}^{95}$.

En definitiva, el reconocimiento de la posibilidad de que la Agencia intervenga en operaciones SAR no solamente constituye un reconocimiento del hecho de que muy a menudo las operaciones coordinadas por Frontex se

92 «Any rules that depart from those in the international regime would be unacceptable, as we would effectively be creating an EU regime that runs in parallel with the international regime but which would be applied in Frontex-coordinated joint operations and insofar as no third countries are involved in the case» (Proposal for a Regulation of the European Parliament and of the Council establishing rules for the surveillance of the external sea borders in the context of operational cooperation coordinated by the European Agency for the Management of Operational Cooperation at the External Borders of the Members States of the European Union, doc. 14612/13, 10 October 2013).

Los principales instrumentos internacionales que regulan las operaciones SAR son los siguientes: el Convenio Internacional para la Seguridad de la Vida Humana en el Mar de 1974 (SOLAS) y el Convenio Internacional sobre Búsqueda y Salvamento Marítimos de 1979 (SAR Convention).

94 Arts. 4 y 8 del Reglamento 2016/1624, loc. cit., supra nota 3.

95 Párr. 45 del preámbulo del Reglamento 2016/1624, loc. cit., supra nota 3. 
convierten en operaciones SAR, sino que tiene también consecuencias prácticas. Tal y como reconoce la Comisión en la propia propuesta del Reglamento 2016/1624, la inclusión de las operaciones SAR dentro del mandato de la nueva Agencia tiene implicaciones presupuestarias porque este tipo de actividades requiere un tipo de equipamiento distinto del utilizado en el marco de las operaciones de vigilancia marítima. En definitiva, no era coherente con el objetivo de desarrollar una estrategia europea de gestión integrada de las fronteras la no inclusión de las operaciones SAR entre las funciones de la Agencia.

Como se ha señalado anteriormente, el Reglamento apenas desarrolla la dimensión de la guardia de costas. Es probable que resulte inevitable llevar a cabo nuevos desarrollos en este ámbito para hacer frente a los desafíos que presentan la vigilancia fronteriza en el mar y las operaciones SAR. Dado que las operaciones SAR se han integrado en el concepto de gestión integrada de las fronteras europeas y se ha otorgado expresamente competencia a Frontex para intervenir en este ámbito ${ }^{96}$, no resultaría complejo desde la perspectiva jurídica reforzar la dimensión de la guardia de costas. A tales efectos, se podría ampliar el objetivo y el ámbito geográfico de las operaciones conjuntas coordinadas por Frontex en el mar, en particular de "Tritón", con el objetivo de incluir también las operaciones SAR en los planes operativos (Carrera et al., 2017). Esta propuesta conduciría a un modelo mixto de responsabilidad entre la GEFC y los Estados miembros, de modo que estos últimos proporcionarían los buques y la GEFC actuaría como coordinador de todas las autoridades nacionales de guardacostas y de defensa implicadas en las operaciones SAR (Carrera et al., 2017). Si continúa en los próximos años la tendencia a dotar a la Agencia de más medios humanos, técnicos y financieros, no sería descartable que estuviera en condiciones de asumir en el futuro plenamente las operaciones SAR en las zonas en las que coordina operaciones conjuntas en el mar. Evidentemente, ha de concurrir la necesaria voluntad política para llevar a cabo esta ambiciosa propuesta.

Tras la creación de la GEFC y la atribución expresa de una competencia en materia SAR cabe plantearse si tiene sentido seguir limitando la aplicación de las normas para la vigilancia de las fronteras marítimas exteriores previstas en el Reglamento 656/2014 a las operaciones conjuntas coordinadas por Frontex. Si bien la responsabilidad primordial en la gestión de las fronteras exteriores sigue correspondiendo a los Estados miembros, la gestión de las fronteras se configura en el Reglamente de la GEFC como una responsabilidad compartida entrre la Agencia y las autoridades nacionales responsables de la gestión de las fronteras. En estas circunstancias, no es descartable que un buque esté sometido a normas más estrictas en relación con la obligación

96 Véanse los arts. 4 y 8 del Reglamento 2016/1624, loc. cit., supra nota 3. 
de respetar el principio de non-refoulement en el caso de que intervenga en el marco de una operación de la Agencia que si interviene en el contexto de una operación desarrollada por ejemplo por la OTAN (Mariani, 2016: 935).

\section{LAS RELACIONES EXTERIORES DE LA AGENCIA}

Las actividades que desarrollan las agencias del ELSJ en el marco de las relaciones con terceros Estados son muy diversas y no han cesado de expandirse en los últimos años (Billet, 2013; Carrera y Parkin et al., 2013; Ott, 2008; Pi Llorens, 2017; Santos Vara, 2015). Frontex es la agencia del ELSJ que ha experimentado un desarrollo más espectacular en la práctica en la cooperación con terceros Estados en los últimos años. Por ello, en la reforma introducida por el Reglamento 1168/2011 se procedió a proporcionar cobertura legal a las prácticas desarrolladas en las relaciones con terceros Estados. Con el objetivo de facilitar la cooperación operativa con las autoridades de terceros Estados se preveía en el Reglamento 1168/2011 que la Agencia podía adoptar varias formas de cooperación con terceros Estados ${ }^{97}$. En primer lugar, se preveía que Frontex podía enviar y recibir funcionarios de enlace sobre una base de reciprocidad, con objeto de contribuir a la prevención y lucha contra la inmigración ilegal y al retorno de emigrantes ilegales, a condición de que se respeten un nivel mínimo de derechos humanos en el tercer país ${ }^{98}$. En segundo lugar, se permitía a Frontex invitar a observadores de terceros países a participar en las iniciativas de la agencia relativas a las operaciones conjuntas y proyectos piloto, análisis de riesgos y formación. En tercer lugar, la Agencia podía beneficiarse de la financiación de la Unión en el marco de las relaciones exteriores con el objetivo de poner en marcha proyectos de asistencia técnica en terceros países. Asimismo, los acuerdos bilaterales concluidos por los Estados miembros con terceros Estados podían incluir disposiciones sobre el papel de la Agencia en el marco de las operaciones conjuntas en terceros Estados ${ }^{99}$. Los instrumentos previstos en el Reglamento de la GEFC para desarrollar la cooperación de la Agencia con terceros Estados son los mismos que ha venido utilizando Frontex en los últimos años ${ }^{100}$. Sin embargo, en el Reglamento de la GEFC se regulan de forma más detallada este

97 Art. 14 del Reglamento 1168/2011, loc. cit., supra nota 13.

98 Ibid.

99 Véase, por ejemplo, el Acuerdo entre España y Cabo Verde sobre vigilancia conjunta de los espacios marítimos bajo soberanía y jurisdicción de Cabo Verde (BOE 136, 5 Junio 2009, p. 47545).

100 Véanse los arts. 54 y 55 del Reglamento 2016/1624, loc. cit., supra nota 3. 
conjunto de instrumentos y se presta una mayor atención al respeto de los derechos humanos y, en particular, al principio de non refoulement.

Los acuerdos de trabajo han constituido un instrumento muy importante para implementar y desarrollar la cooperación operativa de Frontex con terceros Estados (Fink, 2012; Esteve García, 2014; Santos Vara, 2014). Frontex ha hecho un amplio uso de esta competencia al celebrar acuerdos con un gran número de Estados e, incluso, con varias organizaciones internacionales. El contenido de los acuerdos de trabajo concluidos hasta la fecha es bastante similar. Este tipo de acuerdos incluye generalmente un compromiso en materia de intercambio de información, previsiones encaminadas a elaborar y coordinar operaciones conjuntas y proyectos piloto, así como cláusulas relativas a la cooperación en materia de análisis de riesgos, desarrollos técnicos en la gestión de los controles fronterizos y formación. La cooperación con terceros Estados se ha considerado necesaria en aras de promover las normas de la UE en materia de gestión de fronteras, entre las que se confiere actualmente una gran importancia al respeto de los derechos fundamentales.

El procedimiento de celebración de los acuerdos de trabajo no aparecía claramente precisado en las normas constitutivas de Frontex, por lo que era preciso referirse a la práctica desarrollada y a la Decisión del Consejo de Administración de Frontex de 1 de septiembre de 2006, en la que se establecieron las normas para negociar y concluir acuerdos de trabajo con terceros Estados y organizaciones internacionales. Corresponde al director de la Agencia negociar los acuerdos administrativos siguiendo las directrices establecidas por el Consejo de Administración en su mandato de negociación, quien además ha de aprobar finalmente el acuerdo. Asimismo, la Comisión está plenamente implicada en el proceso de negociación de este tipo de acuerdos, pues los proyectos de acuerdo deberán haber sido previamente aprobados por la Comisión ${ }^{101}$. Por lo que se refiere a la participación del Parlamento en la celebración de los acuerdos de trabajo de Frontex, el procedimiento ha experimentado algunos cambios en la reforma del Reglamento de Frontex adoptada en 2011. Mientras que en el Reglamento 2007/2004 no se incluía ninguna referencia al Parlamento Europeo, en el Reglamento 1168/2011 se prevé que «se informará plenamente al Parlamento Europeo sobre estas actividades lo antes posible» ${ }^{102}$. Sin embargo, el Parlamento ha criticado la falta de voluntad de Frontex de cumplir con esta obligación (Spengeman, 2013: 7). En el Reglamento de la GEFC se señala que «la Agencia informará al Parlamento Europeo previamente a la conclusión de

101 Art. 54.2 del Reglamento 2016/1624, loc. cit., supra nota 3.

102 Art. 14.8, Reglamento 1168/2011, loc. cit., supra nota 13. 
los acuerdos de trabajo» ${ }^{103}$. A la luz de las implicaciones que los acuerdos de trabajo de Frontex pueden tener para los derechos humanos, se ha señalado que deberían estar sometidos a la previa aprobación del Parlamento ${ }^{104}$. En mi opinión, al tratarse de meros acuerdos administrativos que se celebran con los servicios de fronteras de terceros Estados, es lógico que no se otorgue al Parlamento un protagonismo mayor (Santos Vara, 2015; Fink, 2012). Además, el control democrático del conjunto de las actividades de Frontex se ha reforzado sustancialmente en el Reglamento de la GEFC (Santos Vara, 2018) ${ }^{105}$. Todos los acuerdos de trabajo celebrados por Frontex contienen una cláusula sobre su estatuto jurídico, en la que se especifica que los acuerdos de trabajo no deben ser considerados tratados internacionales y que su implementación no supone el cumplimiento de obligaciones internacionales por parte de la UE.

En el Reglamento de la GEFC se autoriza por primera vez a la Agencia a llevar a cabo operaciones coordinadas por ella en el territorio de Estados terceros vecinos. Se permite también la participación de terceros Estados en las operaciones conjuntas coordinadas por la Agencia en las fronteras exteriores de los Estados miembros ${ }^{106}$. Evidentemente, este tipo de operaciones solo podrán desarrollarse en el territorio de un tercer Estado vecino si media su autorización previa. Es necesaria la celebración de un acuerdo sobre su estatuto con los terceros Estados afectados para que los equipos de la GEFC gocen de competencias ejecutivas en el territorio de terceros Estados vecinos ${ }^{107}$. Parece que no se ha querido precisar en el Reglamento de la GEFC el concepto de «tercer país vecino», de modo que se identificarán caso por caso. El 22 de noviembre de 2016, la Comisión adoptó un modelo de acuerdo sobre el estatuto para las acciones llevadas a cabo en el territorio de terceros países, y se otorgó prioridad a la celebración de los primeros acuerdos con Serbia y la antigua República de Macedonia ${ }^{108}$. El 8 de marzo de 2017, el Consejo adoptó las

103 Art. 54.2 del Reglamento 2016/1624, loc. cit., supra nota 3.

104 Parliamentary Assembly of the Council of Europe, Frontex: human rights responsibilities, Doc. 13161 (8 Abril de 2013).

105 Son numerosas las disposiciones del Reglamento en las que se obliga a la Agencia a informar al Parlamento Europeo de las actividades realizadas: arts. 54.11, 55.4 del Reglamento 2016/1624, loc. cit., supra nota 3.

106 Art. 54.3 del Reglamento 2016/1624, loc. cit., supra nota 3.

107 En el acuerdo sobre su estatuto se determinará, entre otras cuestiones, «el alcance de la operación, la responsabilidad civil y penal y las funciones y competencias de los miembros de los equipos. El acuerdo sobre su estatuto garantizará el pleno respeto de los derechos fundamentales durante estas operaciones» (art. 54.4 del Reglamento 2016/1624, loc. cit., supra nota 3).

108 COM (2017) 42 final, loc. cit., supra nota 38. 
decisiones que autorizan a la Comisión a iniciar negociaciones con ambos países ${ }^{109}$. Las negociaciones con Serbia han avanzado a buen ritmo y es previsible que se adopte un acuerdo en los próximos meses. Asimismo, la Comisión tiene la intención de presentar al Consejo una propuesta para que le autorice a entablar negociaciones con Albania, Bosnia y Herzegovina y Montenegro.

La posibilidad de llevar a cabo operaciones en el territorio de terceros Estados plantea problemas muy complejos en relación con el régimen jurídico aplicable y la delimitación de responsabilidades entre los diversos actores implicados en las operaciones conjuntas en las que participan terceros Estados (Fink, 201b5; Fernández Rojo, 2017). Tradicionalmente, las operaciones conjuntas coordinadas por Frontex han planteado serias dificultades a la hora de delimitar la responsabilidad entre la Agencia y los Estados miembros participantes. Esta problemática va a adquirir probablemente una mayor complejidad en las operaciones conjuntas que se desarrollen en el territorio de terceros Estados. La delimitación de los respectivos ámbitos de responsabilidad entre los actores implicados ha de ser necesariamente regulada en el plan operativo de la operación que se desarrolle en colaboración con el tercer Estado implicado. Sin embargo, no se precisa en el Reglamento de la GEFC el valor jurídico que tendrá el plan operativo celebrado con un tercer Estado ni tampoco si se puede exigir forzosamente a un tercer Estado su cumplimiento. A la luz de las incertidumbres que presentan este tipo de operaciones, es preciso tener en cuenta que el Reglamento de la GEFC prevé que «la Agencia y los Estados miembros respetarán el Derecho de la Unión, en particular las normas y los requisitos que forman parte del acervo de la Unión, también cuando la cooperación con terceros países tenga lugar en el territorio de los mismos» ${ }^{110}$. Ciertamente, las operaciones desarrolladas en el territorio de terceros Estados no deben servir de excusa para relajar el cumplimiento de las normas europeas en materia de gestión de fronteras y, en particular, el respeto de los derechos fundamentales.

\section{EL NUEVO MECANISMO DE DENUNCIA: UNA SOLUCIÓN INSATISFACTORIA PARA PROTEGER LOS DERECHOS FUNDAMENTALES}

Desde la creación de la Agencia Frontex se ha generado un intenso debate en torno a la protección de los derechos fundamentales en el desarrollo

109 COM (2017) 219 final, loc. cit., supra nota 20.

${ }^{110}$ El art. 54.1 del Reglamento 2007/2004, loc. cit., supra nota 11. 
de las operaciones coordinadas por la Agencia (Guild, 2011; Marin, 2014; Santos Vara, 2015). A este respecto, tanto las instituciones de la UE como la propia Agencia Frontex han alegado constantemente que, en el caso de que se produzcan vulneraciones de los derechos fundamentales en el transcurso de una operación conjunta coordinada por Frontex, cabe exigir únicamente la responsabilidad a los Estados miembros participantes y, en ningún caso, a la propia Agencia, ya que no se le ha atribuido poderes ejecutivos. Sin embargo, es precisamente el rol de liderazgo que asume la Agencia Frontex en el desarrollo y ejecución de las operaciones conjuntas lo que plantea problemas complejos desde la perspectiva de los derechos fundamentales. En estas circunstancias, la eventual responsabilidad de Frontex en relación con la vulneración de los derechos fundamentales constituye un problema jurídico y político que no ha encontrado aún una solución satisfactoria.

La falta de referencia a los derechos humanos en el Reglamento 1168/2004 se basaba en la asunción de que las actividades de Frontex no afectan a los derechos fundamentales porque la Agencia se limitaba a prestar apoyo y facilitar la cooperación operativa entre los Estados en la gestión de las fronteras. Tras la modificación del Reglamento Frontex de 2011, se señalaba constantemente en su norma fundacional que la Agencia estaba obligada a respetar los derechos fundamentales tanto cuando actúa autónomamente como en cooperación con terceros Estados y organizaciones internacionales. Asimismo, Frontex ha emprendido en los últimos años numerosas acciones encaminadas a integrar los derechos fundamentales en todas sus actividades, entre las que destaca la designación del Agente de Derechos Fundamentales $(\mathrm{ADF})$ y la creación del Foro Consultivo sobre derechos humanos que asiste a la Agencia en relación con asuntos relativos a los derechos fundamentales ${ }^{111}$. Destacan también el Plan de Acción en materia de derechos y el Código de conducta, que establecen los estándares que tienen que respetar todas las personas que participan en las actividades de Frontex.

En 2012, el Defensor del Pueblo Europeo llevó a cabo por propia iniciativa una investigación sobre las actividades realizadas por Frontex para examinar la implementación de las obligaciones de derechos fundamentales por parte de la Agencia ${ }^{112}$. Si bien el Defensor del Pueblo reconoció que la protección de los derechos fundamentales había experimentado algunos avances en los años anteriores, puso de manifiesto la inexistencia de un procedimiento

111 Frontex Fundamental Rights Strategy, de 31 de marzo de 2011.

112 Defensor del Pueblo Europeo, Special Report of the European Ombudsman in own-initiative inquiry OI/5/2012/BEH-MHZ concerning Frontex (12 de noviembre 2013). 
para plantear quejas en relación con las eventuales vulneraciones de derechos fundamentales que se produzcan en las actividades Frontex. La propuesta del Defensor del Pueblo fue acogida favorablemente tanto por el Foro Consultivo de Frontex ${ }^{113}$ como por el Parlamento Europeo en $2015^{114}$. Sin embargo, la Agencia no pudo desarrollar este mecanismo al considerar que su Reglamento no le confería atribuciones para poner en marcha una iniciativa de estas características.

El Reglamento de la GEFC ha introducido por primera vez un mecanismo de denuncia con el fin de controlar y garantizar el respeto de los derechos fundamentales en todas las actividades de la Agencia. El art. 72 del Reglamento 2016/1624 prevé que cualquier persona que considere que sus derechos fundamentales han resultado violados en el marco de una operación conjunta, un proyecto piloto, una intervención fronteriza rápida o una operación de retorno, así como cualquier tercero que actúe en su nombre, puede presentar una queja por escrito ante la Agencia. Corresponde al ADF gestionar las reclamaciones recibidas «de conformidad con el derecho a una buena administración ${ }^{115}$. Una vez admitida una denuncia a trámite, el ADF procederá a su registro y la enviará al director ejecutivo de la Agencia o a un Estado miembro para su investigación, según corresponda. En el caso de que la denuncia se refiera a un miembro del personal de la Agencia, el director deberá informar al ADF del seguimiento que se ha llevado a cabo, incluidas las medidas disciplinarias adoptadas si hubiese sido necesario ${ }^{116}$. Si la denuncia se plantea contra un guardia de fronteras de un Estado miembro, este deberá informar igualmente al ADF sobre los resultados de la investigación y las medidas adoptadas ${ }^{117}$. En ambos casos, ha de informarse al denunciante del seguimiento de la investigación, así como de la respuesta proporcionada a la misma.

El mecanismo de denuncia introducido por el Reglamento de la GEFC plantea varios interrogantes. En primer lugar, no se ha precisado qué se entiende por «seguimiento adecuado» y qué formas de reparación se pondrán en el caso de que la denuncia esté bien fundada (Rijpma, 2016b: 30). En segundo lugar, el $\mathrm{ADF}$ tiene que informar al director ejecutivo y al Consejo de Administración sobre el seguimiento que den a las denuncias la Agencia

113 Foro Consultivo de Frontex, Annual Report 2014, p. 38.

114 Parlamento Europeo, Resolución de 2 de diciembre de 2015, sobre el informe especial del Defensor del Pueblo Europeo relativo a su investigación de oficio OI/5/2012/ BEH-MHZ sobre Frontex (2014/2215(INI)).

115 Art. 72.4 del Reglamento 2016/1624, loc. cit., supra nota 3.

116 Art. 72.6 del Reglamento 2016/1624, loc. cit., supra nota 3.

117 Art. 72.7 del Reglamento 2016/1624, loc. cit., supra nota 3. 
y los Estados miembros. Sin embargo, no se especifica en el Reglamento si el ADF dispone de alguna atribución para conminar a la Agencia o a los Estados miembros en el caso de que no se lleve a cabo «un seguimiento adecuado». En tercer lugar, se trata de un mero mecanismo de carácter administrativo que puede conducir únicamente a la adopción de medidas disciplinarias contra el agente responsable de una vulneración de los derechos fundamentales ${ }^{118}$. Un mecanismo de estas características no puede sustituir al derecho a la tutela judicial efectiva, regulado en el art. 47 de la Carta de Derechos Fundamentales, del que es titular toda persona en caso de violación de sus derechos y libertades garantizados por el derecho de la Unión.

Como ha señalado S. Peers (2015: 2), el director ejecutivo de la Agencia, quien está encargado de investigar las quejas dirigidas contra un miembro del personal de la Agencia y de adoptar las eventuales medidas disciplinarias, no es obviamente independiente de la propia Agencia. A este respecto, se ha señalado que el mecanismo de denuncia sería más eficaz si se hubiera atribuido al ADF la competencia para investigar por sí mismo las denuncias presentadas contra el personal de la Agencia, así como ejecutar y hacer cumplir las medidas adoptadas (Fernández Rojo, 2016: 203). En el Reglamento de la GEFC no se contempla ni siquiera la posibilidad de otorgar una compensación por daños en el caso de que se demuestre que los derechos fundamentales del denunciante han sido vulnerados o de interponer una acción penal contra el agente responsable de una vulneración de los derechos fundamentales. Otra de las carencias que presenta el nuevo mecanismo de denuncia es que no se prevé ningún tipo de protección o recurso en el caso de que la denuncia no sea admitida a trámite o los denunciantes consideren que las medidas adoptadas para remediar la vulneración de los derechos fundamentales son insatisfactorias, tal y como propuso el Parlamento. Se prevé únicamente que si la queja no es admitida a trámite, ha de informarse a los denunciantes de los motivos de tal rechazo y se les ofrecerán opciones adicionales para abordar el asunto ${ }^{119}$.

Como se ha señalado anteriormente, tanto la Comisión y Frontex como los Estados miembros han alegado constantemente que la eventual responsabilidad sería atribuible a los Estados miembros, pues Frontex se limita a prestar apoyo y facilitar la cooperación operativa entre los Estados miembros que lo necesiten. A la luz de los nuevos poderes atribuidos a Frontex y, en particular, la eventual sustitución de las autoridades nacionales por la Agencia en la gestión de las fronteras sobre la base del procedimiento previsto en el art. 18

${ }^{118}$ Un mecanismo similar se contemplaba en el antiguo art. 20.5 del Reglamento 2007/2004, loc. cit., supra nota 11.

119 Art. 72.5 del Reglamento 2016/1624, loc. cit., supra nota 3. 
del Reglamento de la GEFC, se desvanece el argumento defendido por las instituciones europeas y los Estados miembros. No es descartable que los agentes del contingente de intervención rápido resulten implicados en situaciones en las que se produzcan vulneraciones de los derechos fundamentales. Asimismo, la gestión de las fronteras se convierte por primera vez en una responsabilidad compartida entre la Agencia y las autoridades nacionales responsables de la gestión de fronteras.

El nuevo marco jurídico establecido por el Reglamento de la GEFC en relación con la eventual responsabilidad de la Agencia y de los Estados miembros en el caso de que se produzcan vulneraciones de los derechos fundamentales ha intensificado los problemas derivados de la eventual responsabilidad compartida entre los Estados miembros y la Agencia, en lugar de resolverlos. No es descartable que este problema se plantee también en las relaciones con Estados terceros. Como se ha señalado anteriormente, la Agencia puede coordinar operaciones conjuntas entre los Estados miembros y terceros Estados que se desarrollarán en las fronteras de los primeros, incluso en el territorio de terceros Estados. En estas circunstancias, la delimitación de la eventual responsabilidad de los actores implicados en el desarrollo de una operación conjunta adquiere una especial complejidad al participar agentes de terceros Estados.

El Tratado de Lisboa introdujo expresamente la posibilidad de plantear un recurso de anulación en relación con los actos de las agencias. En el art. 263 TFUE se prevé que el Tribunal de Justicia «controlará también la legalidad de los actos de los órganos u organismos de la Unión destinados a producir efectos jurídicos frente a terceros». Dentro del concepto de organismo previsto en el art. 263 TFUE se puede incluir a todas las agencias de la UE a excepción de las agencias PESC, pues la competencia del Tribunal de Justicia es excluida en virtud del art. 24 TUE (Billet, 2013: 118). El control judicial de las agencias fue objeto de reflexión en el marco de los trabajos de la Convención Europea con el objetivo de extender el control judicial a todos los actos de las agencias. La Convención Europea consideró que los principios de legalidad y de protección jurisdiccional efectiva exigen que las agencias no queden al margen del control judicial ${ }^{120}$. En realidad, el Tribunal General ya había aceptado antes de la entrada en vigor del Tratado de Lisboa la posibilidad de plantear un recurso de nulidad contra un acto de una agencia en el asunto Solgema ${ }^{121}$. Sin embargo, es preciso tener en cuenta que el Tribunal de Justicia interpreta de forma

120 Convención Europea, Círculo de Discusión sobre el Tribunal de Justicia, documento de trabajo núm. 9 (10 de marzo de 2003).

121 Sentencia de 8 de octubre de 2008, Sogelma, T-411/06, ECLI:EU:T:2008. 
muy restrictiva el acceso a la jurisdicción comunitaria, y no resultará fácil para un particular demostrar que un comportamiento de Frontex le afecta directa e individualmente (Santos Vara, 2018: 453; Pérez González, 2016: 205).

\section{CONCLUSIONES}

El cambio en la denominación de la Agencia da la impresión de que se ha producido una centralización en la gestión de las fronteras, lo cual está aún lejos de suceder. A pesar de que el nuevo Reglamento ha reforzado significativamente las funciones conferidas a la Agencia y de que esta esté en mejores condiciones para hacer frente a futuras crisis en la gestión de las fronteras que en el pasado, esta evolución no supone realmente que se haya producido una transformación en la naturaleza jurídica de la Agencia. Los cambios introducidos en la configuración de la Agencia no se podrían calificar de revolución, sino más bien de evolución natural en el proceso que se inició en 2004 con la creación de Frontex. Además, en el Reglamento de la GEFC se reitera constantemente que la responsabilidad principal en la gestión de las fronteras exteriores corresponde a los Estados miembros.

El proceso de implementación de los nuevos poderes conferidos a la Agencia no ha estado ausente de dificultades. No cabe duda de que la creación de los contingentes de intervención rápida y de equipos técnicos puede contribuir a reforzar la capacidad de la Agencia para responder ante situaciones que requieran una respuesta inmediata. Sin embargo, la Agencia está experimentado dificultades para lograr la plena disponibilidad de los guardias de fronteras que forman parte del contingente de reacción rápida y sigue sufriendo carencias importantes para disponer de los equipos técnicos necesarios para dotar de plena operatividad al contingente de equipos de reacción rápida, a pesar de que ambos contingentes fueron formalmente establecidos en diciembre de 2016.

El examen de vulnerabilidad constituye una de las novedades introducidas por el Reglamento de creación de la GEFC en la que se manifiesta la relación de jerarquía entre la Agencia y las autoridades nacionales encargadas de la gestión de las fronteras. No cabe duda de que el refuerzo de las evaluaciones preventivas constituye un buen instrumento para garantizar el buen funcionamiento del espacio Schengen en el futuro. No obstante, como señala De Bruycker cabe plantearse si la Agencia y, en particular, su director ejecutivo actuarán de forma completamente independiente tanto en el proceso de identificar las vulnerabilidades como a la hora de proponer al Consejo de Administración las medidas necesarias para remediar la situación (De Bruycker, 2016: 563). El denominado «derecho a intervenir» ha generado un intenso debate 
sobre la posibilidad de que la Agencia sustituya a las autoridades nacionales en la gestión de las fronteras exteriores. Como se ha puesto de manifiesto en el presente trabajo, la intervención sin contar con el consentimiento del Estado miembro afectado plantea serias dificultades desde la perspectiva del derecho de la UE. Además, la eventual intervención de la Agencia se ha de basar en el plan operativo elaborado por la Agencia y acordado con el Estado miembro implicado, el cual difícilmente podría ejecutarse sin contar con la colaboración del Estado miembro afectado. En la práctica, el denominado «derecho a intervenir» no se va a materializar generalmente en el envío de equipos de la GEFC por parte de Frontex en sustitución de las autoridades nacionales, sino en la posible exclusión del espacio Schengen del Estado que se muestra reticente a colaborar con las instituciones y la Agencia con arreglo a lo previsto en el art. 26 del Código Schengen.

El Reglamento de la GEFC ha consolidado el papel protagonista de la Agencia en el establecimiento y desarrollo de los hotspots en Grecia e Italia. Se ha procedido a regular por primera vez en un acto jurídico vinculante los hotspots, que constituyen una suerte de administración europea en determinados sectores de las fronteras exteriores que se enfrenta a retos sin precedentes en la gestión de las fronteras. Sin embargo, las previsiones contenidas en el Reglamento de la GEFC en relación con los hotspots no pueden suplir la inexistencia de un marco instrumento jurídico específico en el que se regule de forma omnicomprensiva el marco jurídico de los hotspots. Dado que es probable que siga siendo necesario recurrir a los hotspots en el futuro, no se debe demorar más la adopción de un instrumento en el que se determinen, entre otras cuestiones, las eventuales responsabilidades de las agencias implicadas en caso de que se produzcan violaciones de los derechos humanos.

El refuerzo del papel de la Agencia en materia de retorno constituye una de las novedades más importantes introducidas por el nuevo Reglamento. A tales efectos, se proporciona a la Agencia los equipos europeos de intervención en materia de retorno que se desplegarán durante las operaciones de retorno. La Agencia sigue experimentando dificultades para lograr el número de expertos cualificados requerido. En el Reglamento no se ha proporcionado una respuesta satisfactoria en el caso de que sea preciso determinar la responsabilidad penal o civil de los agentes participantes. Igualmente, el Reglamento de la GEFC refuerza el mandato de la Agencia para el tratamiento de datos de carácter personal, lo cual puede contribuir a lograr una gestión integrada de las fronteras exteriores. Sin embargo, en el marco de las operaciones conjuntas no se delimita claramente la responsabilidad de la Agencia y de los Estados miembros en el tratamiento de los datos personales.

Las autoridades nacionales de guardacostas forman parte también de la GEFC en la medida en que llevan a cabo operaciones de vigilancia de la 
frontera marítima. Sin embargo, la grandilocuencia de la denominación Guardia Europea de Costas no se corresponde con la realidad. La parte dedicada a la Guardia Europea de Costas es sin lugar a dudas el aspecto menos desarrollado del Reglamento. La Guardia Europea de Costas existe únicamente en la denominación del Reglamento 2016/1624, no en la realidad. No están claras las implicaciones prácticas que se derivan de la inclusión de los guardacostas bajo el paraguas de la GEFC. Igualmente, no están tampoco claras las implicaciones prácticas que se pueden derivar de la previsión contenida en el art. 53 de la Reglamento. Se prevé que la Agencia, la AESM y la AECP habrán de intensificar su cooperación tanto entre sí como con las autoridades nacionales en aras de abordar de formar comprehensiva los desafíos y amenazas a las que se enfrentan los Estados miembros en los mares. La vaguedad y la falta de precisión que caracteriza a la Guardia Europea de Costas tienen su origen en la falta de voluntad política para desarrollar esta dimensión de la GEFC. Una buena muestra de la reticencia de los Estados miembros a desarrollar la Guardia Europea de Costas es que en la propuesta original presentada por la Comisión no se incluía, entre las tareas de la Agencia, la intervención en las operaciones SAR que puedan presentarse durante las operaciones de vigilancia de las fronteras marítimas.

Sin lugar a dudas era necesario dotar a la Agencia de la capacidad para desarrollar operaciones conjuntas en el territorio de terceros Estados. No obstante, esta nueva atribución plantea problemas muy complejos en relación con el régimen jurídico aplicable y la delimitación de responsabilidades entre los diversos actores implicados en las operaciones conjuntas en las que participan terceros Estados. Se trata de una cuestión a la que no se ha proporcionado aún una respuesta satisfactoria ni siquiera dentro de la propia UE. Es de esperar que las operaciones conjuntas en el territorio de terceros Estados no se conviertan simplemente en un instrumento más para externalizar la gestión de las fronteras europeas, al margen de los estándares europeos.

La introducción del mecanismo de denuncia individual constituye un desarrollo positivo en aras de proporcionar una respuesta a los problemas derivados de la eventual implicación de la Agencia en vulneraciones de los derechos fundamentales. Sin embargo, el mecanismo de denuncia no proporciona una respuesta satisfactoria a los desafíos que plantean las actividades de Frontex en relación con la protección de los derechos fundamentales. Del mismo modo, el Reglamento de la GEFC no ha contribuido sustancialmente a delimitar la eventual responsabilidad de la Agencia y de los Estados miembros en el caso de que se produzcan vulneraciones de los derechos fundamentales en el transcurso de una operación conjunta coordinada por la Agencia.

El objetivo de la creación de la GEFC es prevenir futuras crisis en la gestión de las fronteras exteriores de la UE, tal y como ha sucedido en Grecia 
e Italia en los últimos años, así como hacer frente a los insuficientes poderes que tenía la Agencia Frontex sobre los Estados miembros. El establecimiento de la GEFC y la expansión de los poderes de la Agencia han generado muchas expectativas. El riesgo es que estas expectativas no se vean plenamente satisfechas en el futuro y que se genere más frustración en la sociedad civil y aumente la falta de credibilidad de la UE si no es capaz de proporcionar soluciones satisfactorias antes los desafíos que se planteen en la gestión de las fronteras en los próximos años. No cabe duda que la UE debería progresar hacia una mayor centralización o federalización en la gestión de las fronteras o al menos hacia un modelo que incluya una mayor solidaridad entre los Estados miembros. Desgraciadamente, no existe aún la voluntad política para progresar hacia este modelo.

\section{Bibliografía}

Billet, C. (2013). Le contrôle des relations extérieures des agences ELSJ après Lisbonne. En C. Flaesh-Mougin y L. Serena Rossi (eds.). La dimensión extérieure de l'espace de liberté, de sécurité et de justice de l'Union Européenne après Lisbonne (pp. 95-129). Bruxelles: Bruylant.

Carrera, S., Blockmans, S., Cassarino, J. P., Gros, D. y Guild, E. (2017). The European Border and Coast Guard. Addressing migration and asylum challenges in the Mediterranean? Brussels: Report of a CEPS Task Force.

— y Den Hertog, L. (2016). A European Border and Coast Guard: What's in a name? Bruessel: CEPS.

— y Parkin, J. (2013). The Peculiar Nature of EU Home Affairs Agencies in Migration Control: Beyond Accountability versus Autonomy. European Journal of Migration and Law, 15, 337-358. Disponible en: https://doi. org/10.1163/15718166-00002040.

Chamon, M. (2015). Les agences, État des lieux et Défis. Cahiers de Droit Européen, 1, 293-318.

De Bruycker, P. (2016). The European Border and Coast Guard: A new Model Built in an old logic. European Papers: A Journal on Law and Integration, 1, 559-569.

Den Heijer, J., Rijpma, J. y Spijkerboer, T. (2016). Coercion, prohibition, and great expectations: The continuing failure of the Common European Asylum System. Common Market Law Review, 53, 607-642.

Esteve García, F. (2014). El refuerzo de Frontex: su actividad exterior y el control de sus actos. En M. Pi Llorens y E. Zapater Duque (coords.). La dimensión exterior de las agencias del espacio de libertad, seguridad y justicia (pp. 37-68). Madrid: Marcial Pons.

Fernández Rojo, D. (2016). Creación de una Guardia Europea de Fronteras y Costas: Breve análisis de la propuesta de Reglamento de la Comisión Europea de 15 de diciembre de 2015. European Papers: A Journal on and Integration, 1, 203-212. 
— (2017). Reglamento 2016/1624: de Frontex a la Guardia Europea de Fronteras y Costas. Revista General de Derecho Europeo, 41, 223-251.

Fink, M. (2012). Frontex Working Arrangements: Legitimacy and Human Rights Concerns Regarding «Technical Relationships». Utrecht Journal of International and European Law, 28, 20-35. Disponible en: https://doi.org/10.5334/ujiel.be. (2015). Salami Slicing Human Rights Accountability: How the European Border and Coast Guard Agency may inherit Frontex' genetic defect. EJIL Analysis [blog], 10-3-2016. Disponible en: https://goo.gl/AGipCz.

González Vega, J. (2017). Mitos y mistificaciones: la Unión Europea y la protección internacional (a propósito de la "crisis de los refugiados»). Revista de Derecho Comunitario Europeo, 56, 27-75. Disponible en: https://doi.org/10.18042/ cepc/rdce.56.02.

Guild, E. et al. (2011). Implementation of the EU Charter of Fundamental Rights and its Impact on EU Home Affairs Agencies. Brussels: Study for the European Parliament's Committee on Civil Liberties, Justice and Home Affairs.

Maiani, F. (2016). Hotspots and Relocation Schemes: the right therapy for the Common European Asylum System? EU Immigration and Asylum Law and Policy [blog], 3-2-2016. Disponible en: https://goo.gl/aPSHVE.

Mariani, S. (2016). The Interception and Resce at Sea of Asylum Seekers in the Light of the New EU Legal Framework. Revista de Derecho Comunitario Europeo, 55, 901-939. Disponible en: https://doi.org/10.18042/cepc/rdce.55.04.

Marin, L. (2014). Policing the EU's External Borders: A Challenge for the Rule of Law and Fundamental Rights in the Area of Freedom, Security and Justice? An Analysis of Frontex Joint Operations at the Southern Maritime Border. Journal of Contemporary European Research, 7, 468-487.

Monar, J. (2006). The Project of a European Border Guard: Origins, Models and Prospects in the Context of the EU's Integrated External Border Management. En M. Caparini y M. Otwin (eds.). Borders and Security Governance. Managing Borders in a Globalised World (pp. 193-208). Geneva: Geneva Centre for the Democratic Control of Armed Forces.

Neville, D., Sy, S. y Rigon, A. (2016). On the frontline: the hotspot approach to managing migration. Study for the European Parliament.

Ott, A. (2008). EU Regulatory Agencies in EU External Relations: Trapped in a Legal Minefield Between European and International Law. European Foreign Affairs Review, 12, 515-540.

Peers, S. (2015). The Reform of Frontex: Saving Schengen at Refugees' Expense? EU Law Analysis [blog], 16-12-2015. Disponible en: https://goo.gl/bTrfYP.

Pérez González, C. (2016). De Frontex a la Agencia Europea de la Guardia de Fronteras y Costas: ¿Cambia todo para que todo siga igual? En C. Blasi Casagran y M. Illamola Dausà (coords). El control de las agencias del Espacio de Libertad, Seguridad y Justicia. Madrid: Marcial Pons.

Pi Llorens, M. (2017). El nuevo mapa de las agencias europeas del espacio de libertad, seguridad y justicia. Revista de Derecho Comunitario Europeo, 56, 77-117. Disponible en: https://doi.org/10.18042/cepc/rdce.56.03. 
Rijpma, J. (2016a). Frontex and the European System of Border Guards: The Future of European Border Management. En M. Fletcher, E. Herlin-Karnell y C. Mattera (eds.). The European Union as an Area of Freedom, Security and Justice. London: Routlegde.

— (2016b). The proposal for a European Border and Coast Guard: evolution or revolution in external border management? Study for the LIBE Committee of the European Parliament.

Rosenfeldt, H. (2016). Establishing the European Border and Coast Guard: all-new or Frontex reloaded? EU Law Analysis [blog], 16-10-2016. Disponible en: https://goo.gl/wNkdAc.

Thym, D. (2016). The «refugee crisis» as a challenge of legal design and institutional legitimacy. Common Market Law Review, 53, 1545-1573.

Tsourdi, L. (2016). Bottom-up Salvation? From Practical Cooperation Towards Joint Implementation Through the European Asylum Support Office. European Papers: a Journal on Law and Integration, 1, 987-1031.

— (2017). Hotspots and EU Agencies: Towards an integrated European Administration? EU Immigration and Asylum Law and Policy [blog], 26-1-2017. Disponible en: https://goo.gl/UCb57F.

Santos Vara, J. (2014). Análisis del marco jurídico-político de la dimensión exterior de la Agencias del Espacio de Libertad, Seguridad y Justicia. En M. Pi Llorens y E. Zapater Duque (coords.). La dimensión exterior de las agencias del espacio de libertad, seguridad y justicia (pp. 9-34). Madrid: Marcial Pons.

— (2015). The External Activities of AFSJ Agencies: The Weakness of Democratic and Judicial Controls. European Foreign Affairs Review, 20, 118-136.

(2018). The EU's agencies. Ever more important for the governance of the Area of Freedom, Security and Justice. En F. Trauner y A. Ripoll Servent (eds.). Routledge Handbook of Justice and Home Affairs Research (pp. 445-455). London: Routlege.

— y Sánchez-Tabernero, S. R. (2016). In Deep Water: Towards a Greater Commitment for Human Rights in Sea Operations Coordinated by FRONTEX? European Journal of Migration and Law, 18, 65-87. Disponible en: https://doi. org/10.1163/15718166-12342090.

Spengeman, A. (2013). Upholding the legitimacy of Frontex: European Parliamentary Oversight. European Security Review, 1-9.

Spijkerboer, T. (2016). Minimalist Reflections on Europe, Refugees and Law. European Papers: a Journal on Law and Integration, 1, 533-558.

Vasquez, M. et al. (2018). Final Report - Study on the feasibility of improved co-operation between bodies carrying out European Coast Guard functions. London: ICF International. 